\title{
Solvent and Water Mediated Structural Variations in Deoxynivalenol and Their Potential Implications on the Disruption of Ribosomal Function
}

\author{
Nora A. Foroud ${ }^{1}$, Roxanne A. Shank ${ }^{2}$, Douglas Kiss ${ }^{2}$, François Eudes ${ }^{2 *}$ and \\ Paul Hazendonk ${ }^{1 *}$ \\ ${ }^{1}$ Lethbridge Research and Development Centre, Agriculture and Agri-Food Canada, Lethbridge, AB, Canada, ${ }^{2}$ Department \\ of Chemistry and Biochemistry, University of Lethbridge, Lethbridge, $A B$, Canada
}

\section{OPEN ACCESS}

Edited by:

Daniela Gwiazdowska,

Poznań University of Economics,

Poland

Reviewed by:

Guilherme Lanzi Sassaki,

Federal University of Paraná, Brazil

Maciej Buśko,

Poznań University of Life Sciences,

Poland

${ }^{*}$ Correspondence:

François Eudes

françois.eudes@agr.gc.ca

Paul Hazendonk

paul.hazendonk@uleth.ca

Specialty section This article was submitted to Fungi and Their Interactions,

a section of the journal

Frontiers in Microbiology

Received: 05 February 2016

Accepted: 25 July 2016

Published: 17 August 2016

Citation:

Foroud NA, Shank RA, Kiss D, Eudes F and Hazendonk P (2016)

Solvent and Water Mediated Structural Variations in Deoxynivalenol and Their Potential Implications on the

Disruption of Ribosomal Function.

Front. Microbiol. 7:1239.

doi: 10.3389/fmicb.2016.01239
Fusarium head blight (FHB) is a disease of cereal crops caused by trichothecene producing Fusarium species. Trichothecenes, macrocylicic fungal metabolites composed of three fused rings $(\mathrm{A}-\mathrm{C}$ ) with one epoxide functionality, are a class of mycotoxins known to inhibit protein synthesis in eukaryotic ribosomes. These toxins accumulate in the kernels of infected plants rendering them unsuitable for human and animal consumption. Among the four classes of trichothecenes (A-D) A and B are associated with FHB, where the type $B$ trichothecene deoxynivalenol (DON) is most relevant. While it is known that these toxins inhibit protein synthesis by disrupting peptidyl transferase activity, the exact mechanism of this inhibition is poorly understood. The three-dimensional structures and $\mathrm{H}$-bonding behavior of DON were evaluated using one- and two-dimensional nuclear magnetic resonance (NMR) spectroscopy techniques. Comparisons of the NMR structure presented here with the recently reported crystal structure of DON bound in the yeast ribosome reveal insights into the possible toxicity mechanism of this compound. The work described herein identifies a water binding pocket in the core structure of DON, where the $3 \mathrm{OH}$ plays an important role in this interaction. These results provide preliminary insights into how substitution at $\mathrm{C}_{3}$ reduces trichothecene toxicity. Further investigations along these lines will provide opportunities to develop trichothecene remediation strategies based on the disruption of water binding interactions with $3_{\mathrm{OH}}$.

Keywords: deoxynivalenol (DON), fusarium head blight (FHB), fusarium graminearum, NMR spectroscopy, mycotoxins, chemical structure

\section{INTRODUCTION}

Deoxynivalenol (DON) belongs to a class mycotoxins called trichothecenes and are produced by Fusarium species involved cereal crop diseases, such as Fusarium head blight (FHB; Foroud and Eudes, 2009). The responsible fungal species infect wheat and other small grains during flowering and kernel development stages and mycotoxins accumulate in the kernels of infected plants (Foroud et al., 2014). Ingestion of trichothecene-contaminated grain is harmful for human and animal consumers (Pestka, 2010). Trichothecenes are known to induce programmed cell 
death (apoptosis) by exerting ribotoxic effects on eukaryotic cells (Shifrin and Anderson, 1999; Rocha et al., 2005). Interestingly, like many antibiotics, trichothecenes interfere with ribosome function, and act as potent inhibitors of protein synthesis in eukaryotes (Ueno et al., 1968; McLaughlin et al., 1977). Earlier it was hypothesized that trichothecenes make direct contact with the ribosomal protein RPL3 (Gilly et al., 1985). Moreover, three domains of RPL3 function as a "rocker switch" that dynamically coordinates amino acyl-tRNA (aa-tRNA) and ribosome during translation elongation (Meskauskas and Dinman, 2008)-thus, an interaction of these toxins with RPL3 would result in an inhibition of protein synthesis. This hypothesis was validated in yeast where W225C or W225R mutations in the highly conserved W-finger of RPL3 conferred toxin resistance (Mitterbauer et al., 2004). The close proximity of RPL3 with the peptidyl transferase center (PTC) suggests that trichothecenes interfere directly with peptidyl transferase activity (Mitterbauer et al., 2004). Recent $\mathrm{x}$-ray crystallography studies of toxin-bound yeast ribosomes, clearly shows trichothecene (DON, T-2 toxin and verrucarin A) binding to the A-site of the PTC (Garreau De Loubresse et al., 2014), which would impair peptide bond formation during translation elongation.

The most effective method to minimize trichothecene contamination of food/feed grain is to grow cultivars with FHB resistance and to employ strategic disease management practices, such as those previously described (Dill-Macky and Jones, 2000; Krupinsky et al., 2002; McMullen et al., 2008, 2012; Foroud et al., 2014). A major challenge is that "immunity" to FHB has not been identified in cultivated cereals, and the availability of highly resistant cultivars is limiting since resistance tends to be associated with poor agronomics (Foroud et al., 2014). Ongoing efforts have led to some improvements over the years (for an overview see McMullen et al., 2012, and other publications in the current issue of Frontiers in Microbiology), meanwhile FHB continues to have significant impact. Furthermore, no remediation strategies are available for detoxification or sequestration of trichothecenes. That being said, grain cleaning strategies can be employed to remove some of the contaminated roughage from the grain (Tittlemier et al., 2014) and biological mechanisms to detoxify trichothecenes have been identified (Fuchs et al., 2002; Poppenberger et al., 2003; Boutigny et al., 2008).

Trichothecenes are composed of three fused rings: the cyclohexene (A-ring) is fused to the tetrahydropyran (B-ring), which is bridged by a 2-carbon chain at $\mathrm{C}_{2}$ and $\mathrm{C}_{5}$ thereby forming a cyclopentyl moiety (C-ring). In addition, an epoxide functionality is attached at $\mathrm{C}_{12}$ which is common to the Band C-rings (Scheme 1) (Cole and Cox, 1981). Side chains at $\mathrm{C}_{3}, \mathrm{C}_{4}, \mathrm{C}_{7}, \mathrm{C}_{8}$, and $\mathrm{C}_{15}$ are variable, although primarily consist of $\mathrm{H}, \mathrm{OH}$, or $\mathrm{OC}(=\mathrm{O}) \mathrm{CH}_{3}$. Trichothecenes fall into four classes (types A-D) (McCormick et al., 2011), where either A and $\mathrm{B}$ are produced by Fusarium species. DON is a type B trichothecene, which is characterized by a ketone at $\mathrm{C}_{8}$, and has hydroxyl groups at $\mathrm{C}_{3}, \mathrm{C}_{7}$, and $\mathrm{C}_{15}$. The epoxide ring is essential for toxicity (Ehrlich and Daigle, 1987). which are unusually stable in the trichothecenes (Pronyk et al., 2006; Bullerman and Bianchini, 2007). Some bacterial species can open the epoxide ring, forming de-epoxynivalenol (DOM-1) (Fuchs et al., 2002; Schatzmayr et al., 2006). No de-epoxy trichothecenes have been reported in plants infected with trichothecene-producing Fusarium species. Other modifications, in planta, that show reduced toxicity include DON-thiol, and -glucoside conjugates (Gardiner et al., 2010; Kluger et al., 2013; Stanic et al., 2015). The former were observed at $\mathrm{C}_{9}$, disrupting the double bond in the A-ring (Kluger et al., 2013), and at $\mathrm{C}_{8}$, disrupting the $\mathrm{R} 5$ keto functional group at Gardiner et al. (2010). The latter are catalyzed by plant UDPglucostranferases that yield DON-3-glucosides (Poppenberger et al., 2003). Generally, modifications at $\mathrm{C}_{3}$ reduces toxicity; for example, acetylation, produces 3-O-acetyl-DON which is significantly less toxic than DON (Desjardins et al., 2007; McCormick, 2009).

Structural knowledge of trichothecenes has driven detoxification/remediation strategies. Trichothecenes from all classes have been studied primarily in chloroform (Cole and Cox, 1981; Savard et al., 1987; Greenhalgh et al., 1989), which obviously does not emulate their biological environment. A single report on the effect of solvent DON and NIV structures provides compelling evidence for significant structural variation in different chemical environments. Jarvis et al. (1990) provided preliminary evidence for a second minor configuration in a single crystal X-ray diffraction (SCXRD) study of NIV recrystallized from a mixture of methanol- $\mathrm{d}_{4}\left(\mathrm{CD}_{3} \mathrm{OD}\right)$ and water. The authors compared changes in ${ }^{13} \mathrm{C}$ nuclear magnetic resonance (NMR) spectra of both $\mathrm{DON}$ and NIV in $\mathrm{CDCl}_{3}$ with those in acetone- $\mathrm{d}_{6}, \mathrm{CD}_{3} \mathrm{OD}$, and DMSO- $\mathrm{d}_{6}$, and proposed that the second configuration in both toxins is an isomer resulting from a rearrangement of the ketone at $\mathrm{C}_{8}$ and hydroxyl at $\mathrm{C}_{15}$ to a hemiketal linkage between $\mathrm{C}_{8}$ to $\mathrm{C}_{15}$.

Historically, $\mathrm{CDCl}_{3}$ was the solvent of choice as most trichothecenes are soluble in it, and it seems to minimize problems associated with aggregation which is at the heart of their poor solubility in water. Chloroform is a significant departure from the cellular environment. Although the cytosol is primarily aqueous, some hydrophobic environments with limited free water exist. As such, trichothecene structure and dynamics should be observed in both types of environments, where the presence of free water is controlled to gain a better understanding of how these toxins interact with and move through the cell.

A more comprehensive structural analyses and a dynamic understanding of the trichothecene-ribosome interaction and inhibition mechanisms will lead to more advancements in this area. With some exceptions, the majority of the structural analysis of trichothecenes reported to date was carried out 2030 years ago, and often with the purpose of basic structural determination and identification. Technological advances in structural determination have made it possible to perform more detailed structural analysis and dynamics. A small number of dynamic studies have been reported among the different classes of trichothecenes (Jarvis et al., 1990; Fragaki et al., 2008; Steinmetz et al., 2008; Chaudhary et al., 2011; Shank et al., 2011). Density functional theory (DFT) computations were carried out by Nagy et al. (2005), on the internal dynamics 


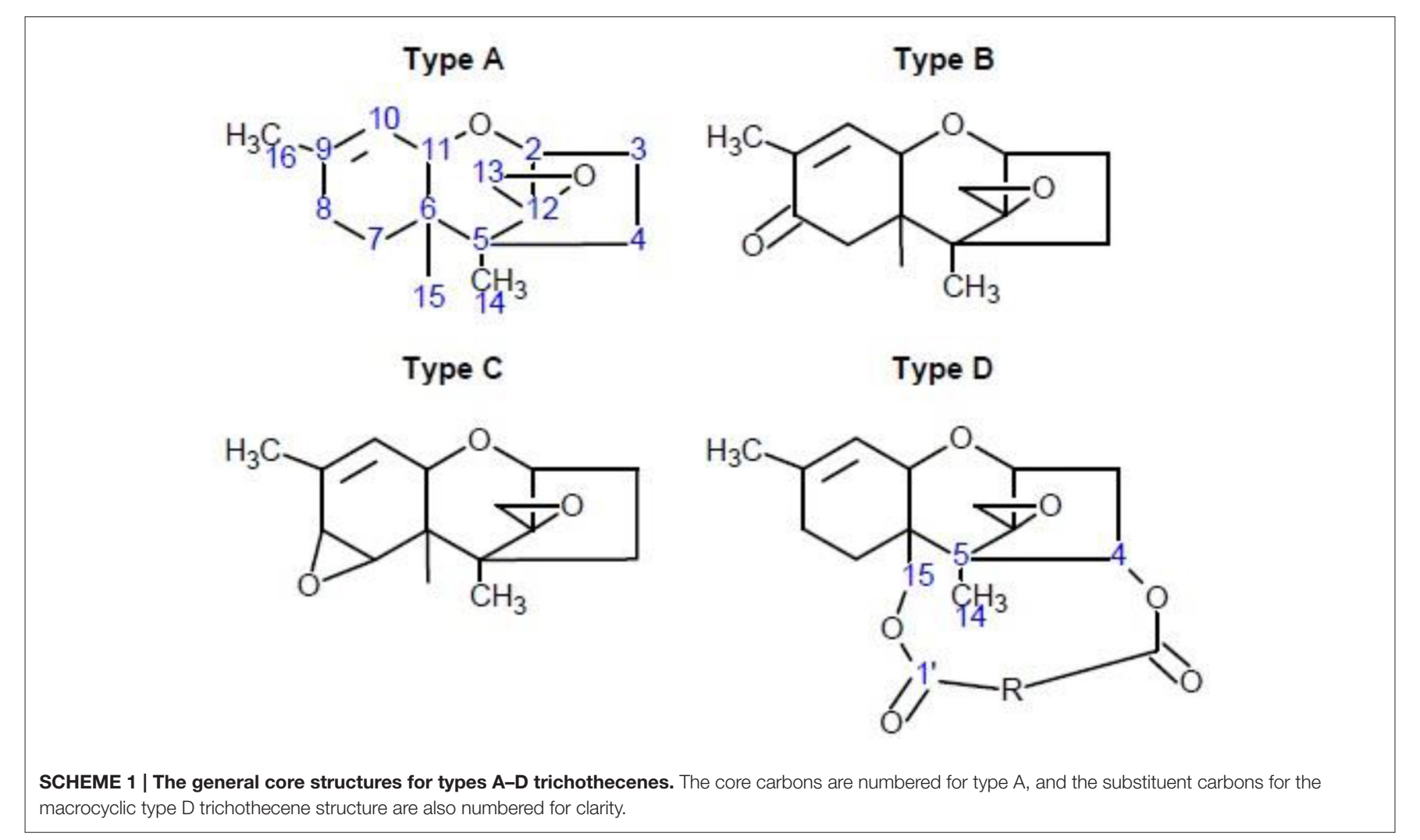

SCHEME 1 | The general core structures for types A-D trichothecenes. The core carbons are numbered for type A, and the substituent carbons for the
macrocyclic type D trichothecene structure are also numbered for clarity.

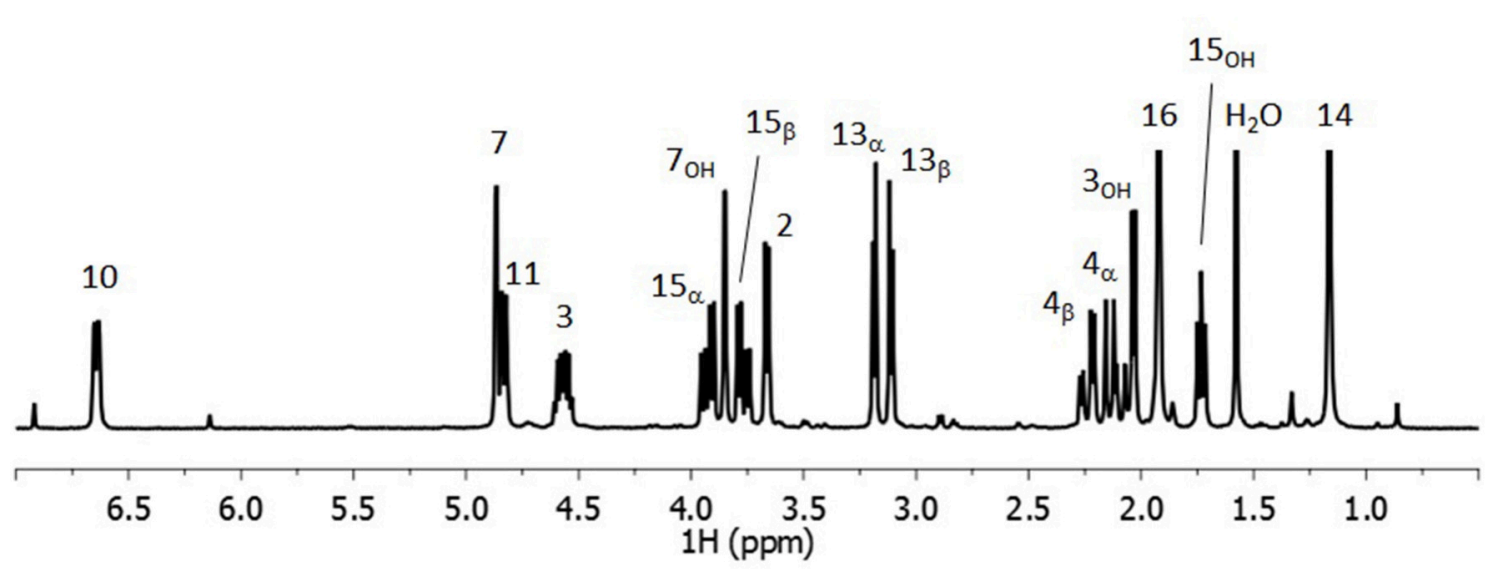

FIGURE 1 | $300 \mathrm{MHz}^{1} \mathrm{H}$ of DON in dried $\mathrm{CDCl}_{3}$.

of DON, which suggested that the lowest energy configuration contains an internal $\mathrm{H}$-bonding network. The proposed $\mathrm{H}$ bonding occurs between the $\mathrm{C}_{8}$ carbonyl oxygen and the $\mathrm{C}_{7}$ hydroxyl hydrogen, which in turn is linked to the hydroxyl hydrogen at $\mathrm{C}_{15}$. The energy of this interaction is significantly lower than all other locally optimal configurations considered; however, H-bonding and bridging with water was not taken into account in this study. Also recent evidence presented by our group on water binding in T-2 toxin (Chaudhary et al., 2011) demonstrates that the H-bonding networks, both intra- and inter-molecular, of all the trichothecenes should be carefully considered.

The current study was designed to determine whether different solvent properties induce structural changes in DON, where the presence of free and bound water is controlled. High resolution ${ }^{1} \mathrm{H}$ and ${ }^{13} \mathrm{C}$ solution state spectra are presented which provides novel insights into the structure and dynamics of DON in different chemical environments. The structural implications on the toxicity mechanisms and biological interactions of DON are discussed. 
TABLE 1 | Chemical shifts (ppm) for $\mathrm{DON}$ in $\mathrm{CDCl}_{3}$ compared with literature.

\begin{tabular}{|c|c|c|c|c|}
\hline${ }^{1} \mathrm{H}$ & Exp. & Lit. $^{a}$ & cosyb & NOESYd \\
\hline 2 & 3.671 & 3.62 & $3,4_{\alpha}, 11,14$ & 3 \\
\hline 3 & 4.577 & 4.53 & $2,3_{\mathrm{OH}}, 4_{\alpha \beta}$ & $2,4_{\alpha \beta}$ \\
\hline${ }^{3} \mathrm{OH}$ & 2.066 & N.O. ${ }^{\mathrm{C}}$ & 3 & $15_{\mathrm{OH}}, \mathrm{W}$ \\
\hline $4_{\alpha}$ & 2.129 & 2.21 & $2,3,4_{\beta}, 11$ & $3,4_{\beta}, 14$ \\
\hline $4_{\beta}$ & 2.247 & 2.07 & $3,4_{\alpha}, 11,13_{\beta}, 14$ & $2,3_{\mathrm{oH}}, 4_{\alpha}, 11,15_{\alpha \beta}$ \\
\hline 7 & 4.876 & 4.83 & ${ }^{7} \mathrm{OH}$ & ${ }^{7} \mathrm{OH}$ \\
\hline${ }^{7} \mathrm{OH}$ & 3.861 & N.O. & 7 & $7,14, \mathbf{W}$ \\
\hline 10 & 6.652 & 6.61 & 11,16 & 11,16 \\
\hline 11 & 4.843 & 4.80 & $2,4_{\alpha \beta}, 10,15_{\alpha \beta}, 16$ & $2,3_{\mathrm{OH}}, 4_{\beta}, 10,15_{\alpha \beta \mathrm{OH}}, 16$ \\
\hline $13_{\alpha}$ & 3.195 & 3.07 & $13_{\beta}$ & $13_{\beta}, 14$ \\
\hline $13_{\beta}$ & 3.121 & 3.15 & $13_{\alpha}, 4_{\beta}$ & $2,13_{\alpha}$ \\
\hline 14 & 1.170 & 1.13 & $2,4_{\beta}$ & $4_{\alpha}, 7_{\mathrm{OH}}, 15_{\alpha}$ \\
\hline $15_{\alpha}$ & 3.932 & 3.73 & $15_{\beta}, 15_{\mathrm{OH}}, 11$ & $4_{\beta}, 14,15_{\beta}, 15_{\mathrm{OH}}$ \\
\hline $15_{\beta}$ & 3.778 & 3.89 & $15_{\alpha}, 15_{\mathrm{OH}}, 11$ & $4_{\beta}, 11,14,15_{\alpha}, 15_{\mathrm{OH}}$ \\
\hline $15 \mathrm{OH}$ & 1.759 & N.O. & $15_{\alpha}, 15_{\beta}$ & $3_{\mathrm{OH}}, 15_{\alpha \beta}, \mathbf{W}$ \\
\hline 16 & 1.930 & 1.86 & 10,11 & 10 \\
\hline
\end{tabular}

a Savard and Blackwell (1994).

${ }^{b}$ EXSY crosspeaks are in blue.

${ }^{c}$ Not observed.

${ }^{d}$ NOESY crosspeaks of note are in red.

\section{MATERIALS AND METHODS}

\section{Materials}

4-Deoxynivalenol was purchased from Sigma, (DON; CAS 51481-10-8), with estimated purity $>95 \%$. The delivered sample, which had a flaky appearance, was dried under dynamic vacuum to remove residual water.

NMR samples of DON were prepared in $\mathrm{CDCl}_{3}$ to a concentration of $1 \mathrm{mg} \mathrm{mL}^{-1}$ with TMS as an internal reference for both ${ }^{13} \mathrm{C}$ and ${ }^{1} \mathrm{H}$. $\mathrm{CDCl}_{3}$ was dried over molecular sieves to prevent further introduction of water through the solvent. A sample was also prepared in dried DMSO- $\mathrm{d}_{6}$; however for the samples in acetone- $\mathrm{d}_{6}, T H F-\mathrm{d}_{4}$ and methanol- $\mathrm{d}_{4}$ the solvents were not dried. All deuterated solvents were purchased from Sigma-Aldrich.

\section{${ }^{1} \mathrm{H}$ Solution-State NMR Experiments}

All NMR spectra were acquired using a Bruker Avance 2 $300 \mathrm{MHz}$ spectrometer, outfitted with a $5 \mathrm{~mm}$ HX PABBO $\mathrm{BB}$ probe. The magnetic field strength is 7.05 Tesla, with larmor frequencies of $300.13 \mathrm{MHz}$ for ${ }^{1} \mathrm{H}$. All experiments were performed at ambient temperature $\left(25^{\circ} \mathrm{C}\right)$. Typical $1 \mathrm{D}^{1} \mathrm{H}$ spectra were recorded as 128 transients, using a $90^{\circ}$ pulse width of 12.4 $\mu \mathrm{s}$, and a recycle delay of $1.5 \mathrm{~s}$. Similarly typical $1 \mathrm{D}{ }^{13} \mathrm{C}$ spectra were obtained in 4000 transients, using a $90^{\circ}$ pulse width of 7.6 $\mu \mathrm{s}$, and a recycle delay of $4.0 \mathrm{~s}$, as $64 \mathrm{~K}$ points over a spectral window of $18 \mathrm{kHz}$.

The homonuclear magnitude gradient ${ }^{1} \mathrm{H}$ COSY spectrum was acquired in 256 increments over a spectral width of $1800 \mathrm{~Hz}$ $(12.0 \mathrm{ppm})$ in both dimensions, using a recycle delay of 1.5 s. 64 transients were collected for each increment, having 4096 points.
The direct and indirect dimensions have a digital resolution of 0.88 and $7.03 \mathrm{~Hz}$, respectively, before zero filling.

The gradient ${ }^{1} \mathrm{H}$ NOESY spectrum was acquired in at least 256 increments covering a spectral width of $1802.45 \mathrm{~Hz}(12.0 \mathrm{ppm})$ in both dimensions, using a recycle delay of $20 \mathrm{~s}$ and an array of mixing times of $0.5,1.0,2,5,7$, and $10 \mathrm{~s}$. Eight transients were collected for each increment, having 4096 points. The direct and indirect dimensions have a digital resolution of 0.88 and $7.03 \mathrm{~Hz}$, respectively, before zero filling. Inversion recovery experiments determined that the $\mathrm{T}_{1} \mathrm{~s}$ of all $\mathrm{DON}$ and water signals were below $3 \mathrm{~s}$.

The ${ }^{1} \mathrm{H}_{-}{ }^{13} \mathrm{C}$ HSQC spectrum was acquired in 128 increments, using a recycle delay of $2.0 \mathrm{~s}$, and a spectral width of $4006.41 \mathrm{~Hz}$ (13.34 ppm) in the direct dimension and $12,500 \mathrm{~Hz}(165.62 \mathrm{ppm})$ in the indirect dimension. 152 transients were collected for each increment, having 1024 points, which was zero filled to 4096 points. The $t_{1}$ dimension was linear forward predicted to 256 points and further zero filled to 1024 points. The direct and indirect dimensions have a digital resolution of 3.9 and $98 \mathrm{~Hz}$, respectively.

The ${ }^{1} \mathrm{H}-{ }^{13} \mathrm{C}$ HMBC spectrum was acquired in 256 increments using a recycle delay of $2.0 \mathrm{~s}$, and a spectral width covering $1951.60 \mathrm{~Hz}(6.50 \mathrm{ppm})$ in the direct dimension and $14,268 \mathrm{~Hz}$ $(190.24 \mathrm{ppm})$ in the indirect dimension. One-hundred transients were collected for each increment, having 1024 points and the FID was zero-filled up to a value of 4096 points. The $t_{1}$ dimension was linear forward predicted to 512 points and further zero filled to 1024 points. The direct and indirect dimensions have a digital resolution of 0.52 and $56 \mathrm{~Hz}$, respectively.

Drying experiments were performed at ambient temperature by sequential addition of individual molecular sieves to the NMR tube between consecutive NMR measurements, over the course of $3 \mathrm{~h}$ where the water to DON ratio was monitored over a period of $72 \mathrm{~h}$.

\section{Simulations}

The SpinWorks processing and simulation software suite, developed by Marat (2009) at the University of Manitoba, was used to simulate the data obtained for the $300 \mathrm{MHz}{ }^{1} \mathrm{H}$ spectra. The FIDs were zero-filled to $256 \mathrm{~K}$ points and were subjected to Gauss-Lorentz apodization with a line broadening between -1.00 to $-0.50 \mathrm{~Hz}$, and a Gaussian broadening of 0.33 , depending on the signal-to-noise ratio in the data. The spectra were simulated in two parts as the whole spin system could not be simulated at once. The sub-spectrum of the six-membered ring was simulated as a 10 -spin $\mathrm{ABC}_{3} \mathrm{DEFG}$ system using $7_{\mathrm{OH}}, 7_{\beta}, 10,11,15_{\alpha}, 15_{\beta}, 15_{\mathrm{OH}}$, 16. Similarly, the sub-spectrum associated with the remaining hydrogens: $2,3,3_{\mathrm{OH}}, 4_{\alpha}, 4_{\beta}, 14,13_{\alpha}$, and $13_{\beta}$ was simulated as a ten-spin $\mathrm{ABCDEF}_{3} \mathrm{GH}$ spin system. Long range couplings were considered up to five bonds, and an inherent line-width of 0.3 $\mathrm{Hz}$ along with Gaussian line shapes was used to fit the data. In the A-ring simulation typically 2000 transitions were assigned to within RMS deviations below $0.03 \mathrm{~Hz}$, and a largest absolute differences of less than $0.08 \mathrm{hz}$ Standard deviations (SD) in all the spectral parameters ranged from 0.1000 to $0.001 \mathrm{hz}$ In the $\mathrm{C}$ ring simulation, typically 2200 transitions were assigned with an RMS deviations below $0.03 \mathrm{~Hz}$, and largest absolute differences less 


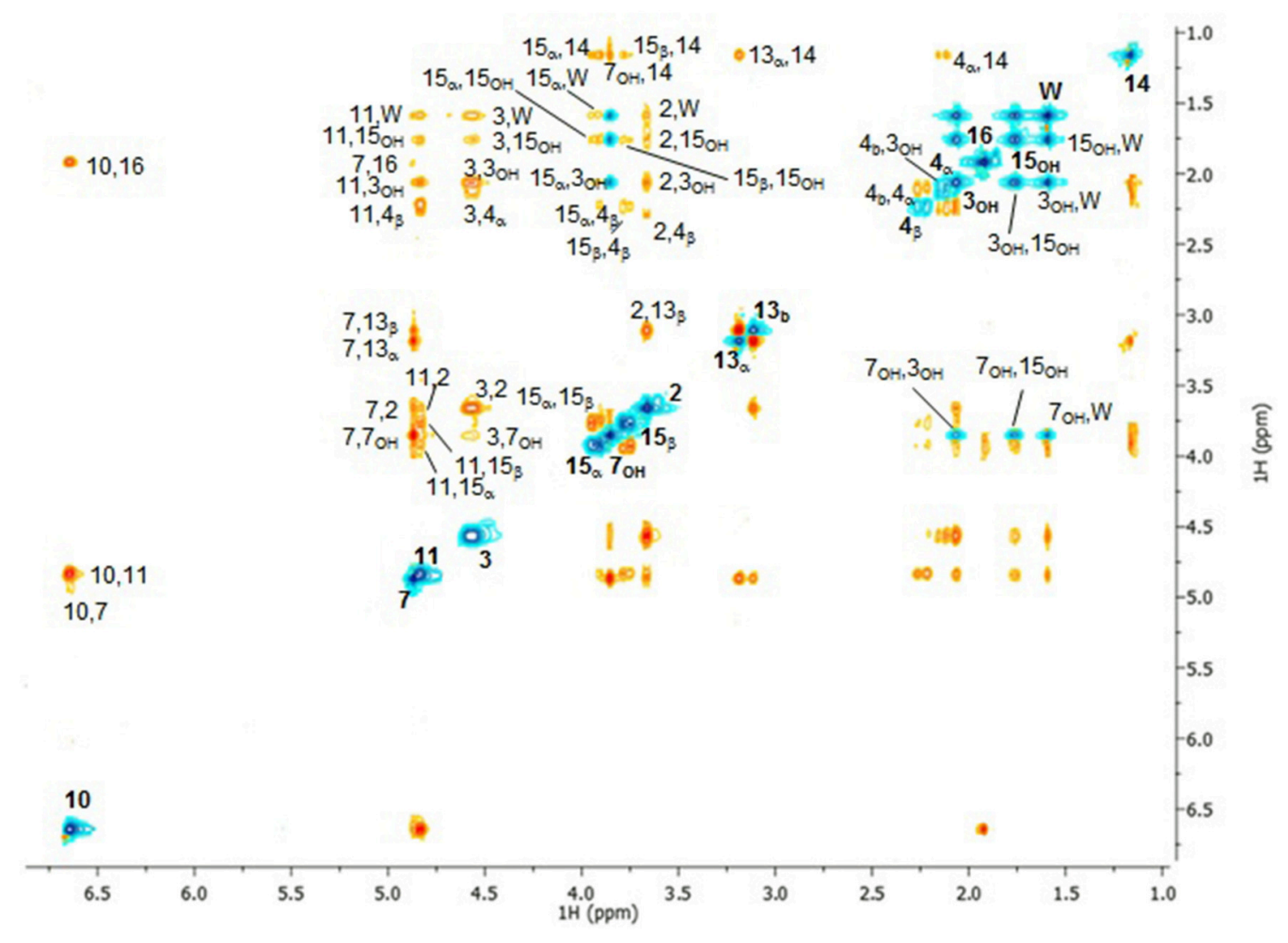

FIGURE 2 | $300 \mathrm{MHz}^{1} \mathrm{H}$ NOESY of DON in $\mathrm{CDCl}_{3}$ with a mixing time of $3 \mathrm{~s}$.

than $0.09 \mathrm{hz}$ SD in all the spectral parameters range from 0.1000 to $0.001 \mathrm{~Hz}$.

\section{Structural Analysis}

All proposed structures were calculated and optimized using ACD ChemSketch, from which internuclear distances were estimated for comparison to those obtained from the NOESY spectra in $\mathrm{CDCl}_{3}$, and DMSO- $\mathrm{d}_{6}$. All NOESY spectra were analyzed using Mestre NOVA software, using an LB of $3 \mathrm{~Hz}$ in each dimension. Integration of all the cross-peaks $(\mathrm{CP})$ and autocorrelation peaks (ACP) was performed from which the CP to $\mathrm{ACP}$ ratio were computed and the cross-relaxation rate, $s$, was obtained using:

$$
\tan \mathrm{h}^{-1}\left(\frac{\mathrm{I}_{\mathrm{CP}}}{\mathrm{I}_{\mathrm{ACP}}}\right)=\sigma \tau_{\text {mix }}
$$

The cross-relaxation rates were used to determine the internuclear distances, using $4_{\alpha}$ and $4_{\beta}$ as well as $13_{\alpha}$ and $13_{\beta}$ as references with internuclear distances of 181 and $186 \mathrm{pm}$ respectively. The following relationship was used:

$$
r_{i j}=r_{r e f} \sqrt[6]{\frac{\sigma_{r e f}}{\sigma_{i j}}}
$$

The EXSY CP were used to compute exchange rates between water and $\mathrm{OH}$ signals using:

$$
\tan \mathrm{h}^{-1}\left(\frac{\mathrm{I}_{\mathrm{CP}}}{\mathrm{I}_{\mathrm{ACP}}}\right)=k \tau_{\text {mix }}
$$

\section{RESULTS}

\section{Full Spectral Assignment of DON in Chloroform}

The assignment of the ${ }^{1} \mathrm{H}$ spectrum in $\mathrm{CDCl}_{3}$ differed significantly from those in previous reports on the basis of spectral simulation and new evidence from the COSY and NOESY spectra. In addition to the revision of the methylene proton assignments, accurate chemical shifts of the hydroxyl protons are offered here.

The ${ }^{1} \mathrm{H}$ spectrum of $\mathrm{DON}$ in $\mathrm{CDCl}_{3}$ is shown in Figure 1 in which the labeling convention of Savard et al. (1987) was employed as shown in Scheme 1. Where significant $\pi$-electron delocalization is expected, coupling constants of up to five-bonds were considered. The assignment of the ${ }^{1} \mathrm{H}$ spectrum is given in Table 1 where the chemical shifts and coupling constants given alongside the diagnostic homonuclear CP from the COSY and the NOESY spectra. Figure 2 contains the NOESY spectrum of $\mathrm{DON}$ in $\mathrm{CDCl}_{3}$ measured using a mixing time of $3 \mathrm{~s}$. The most 
TABLE 2 | Internuclear distances calculated from NOESY spectrum in $\mathrm{CDCl}_{3}$, at a mixing time of $3 \mathrm{~s}$, compared with computed boat and chair geometries.

\begin{tabular}{|c|c|c|c|c|c|c|}
\hline \multirow{2}{*}{$\frac{\boldsymbol{N}_{\mathbf{i}}^{\mathbf{a}}}{2}$} & \multirow{2}{*}{$\frac{\boldsymbol{N}_{\mathbf{j}}}{3}$} & \multirow{2}{*}{$\frac{\boldsymbol{r}_{\mathbf{i j}}^{\mathbf{b}}}{2.06}$} & \multicolumn{2}{|c|}{$r_{\mathrm{ij}}\left(\right.$ boat) ${ }^{\mathrm{c}}$} & \multicolumn{2}{|c|}{$r_{\mathrm{ij}}\left(\right.$ chair) ${ }^{\mathrm{c}}$} \\
\hline & & & 2.34 & $0.08^{d}$ & 2.36 & $0.09^{d}$ \\
\hline 2 & 7 & 3.97 & 5.20 & 1.52 & 3.92 & 0.00 \\
\hline 2 & $13_{\beta}$ & 2.30 & 2.50 & 0.04 & 2.53 & 0.05 \\
\hline 2 & $15_{\alpha}$ & 3.70 & 4.44 & 0.55 & 5.31 & 2.59 \\
\hline 2 & ${ }^{3} \mathrm{OH}$ & 2.56 & 2.87 & 0.09 & 2.74 & 0.03 \\
\hline 2 & $4_{\beta}$ & 3.68 & 4.23 & 0.30 & 4.26 & 0.34 \\
\hline 2 & W & 2.99 & & & & \\
\hline 3 & ${ }^{3} \mathrm{OH}$ & 2.11 & 2.75 & 0.41 & 2.24 & 0.02 \\
\hline 3 & $4_{\alpha}$ & 1.77 & 2.25 & 0.24 & 2.29 & 0.27 \\
\hline 3 & $4_{\beta}$ & 3.06 & 2.91 & 0.02 & 2.91 & 0.02 \\
\hline 3 & W & 2.84 & & & & \\
\hline 7 & 10 & 3.72 & 4.13 & 0.17 & 4.14 & 0.17 \\
\hline 7 & $13_{\alpha}$ & 2.11 & 2.20 & 0.01 & 1.76 & 0.12 \\
\hline 7 & $13_{\beta}$ & 2.42 & 3.92 & 2.25 & 2.39 & 0.00 \\
\hline 7 & ${ }^{7} \mathrm{OH}$ & 2.21 & 2.20 & 0.00 & 2.28 & 0.00 \\
\hline 10 & 11 & 2.09 & 2.90 & 0.65 & 2.54 & 0.20 \\
\hline 10 & 16 & 3.10 & 2.96 & 0.02 & 3.03 & 0.01 \\
\hline 11 & 2 & 2.91 & 4.16 & 1.57 & 3.57 & 0.44 \\
\hline 11 & $15_{\alpha}$ & 2.70 & 2.65 & 0.00 & 2.81 & 0.01 \\
\hline 11 & $15_{\beta}$ & 2.44 & 2.35 & 0.01 & 2.61 & 0.03 \\
\hline 11 & $3_{\mathrm{OH}}$ & 2.53 & 2.79 & 0.07 & 2.37 & 0.02 \\
\hline 11 & $4_{\beta}$ & 1.97 & 4.13 & 4.65 & 2.46 & 0.24 \\
\hline 11 & W & 3.14 & & & & \\
\hline 14 & $13_{\alpha}$ & 2.87 & 3.04 & 0.03 & 3.10 & 0.05 \\
\hline 14 & $7_{\mathrm{OH}}$ & 2.98 & 3.67 & 0.48 & 3.58 & 0.37 \\
\hline $13_{\alpha}$ & $13_{\beta}$ & 1.76 & 1.87 & 0.01 & 1.88 & 0.01 \\
\hline $15 \alpha$ & $15_{\beta}$ & 2.00 & 1.81 & 0.03 & 1.80 & 0.04 \\
\hline $15 \alpha$ & $15 \mathrm{OH}$ & 2.46 & 2.24 & 0.05 & 2.71 & 0.06 \\
\hline $15_{\alpha}$ & $4_{\beta}$ & 2.35 & 1.89 & 0.21 & 1.91 & 0.20 \\
\hline $15 \alpha$ & W & 2.93 & & & & \\
\hline $15_{\beta}$ & $15 \mathrm{OH}$ & 2.59 & 2.29 & 0.09 & 2.78 & 0.04 \\
\hline $15_{\beta}$ & $4_{\beta}$ & 2.98 & 3.32 & 0.11 & 3.23 & 0.06 \\
\hline $15_{\beta}$ & W & 3.22 & & & & \\
\hline${ }^{3} \mathrm{OH}$ & $4_{\beta}$ & 2.45 & 2.91 & 0.22 & 3.37 & 0.84 \\
\hline $4_{\alpha}$ & 14 & 2.48 & 2.94 & 0.22 & 2.99 & 0.26 \\
\hline $4_{\alpha}$ & $4_{\beta}$ & 1.81 & 1.82 & 0.00 & 1.82 & 0.00 \\
\hline${ }^{7} \mathrm{OH}$ & $13_{\alpha}$ & 2.49 & 4.36 & 3.52 & 2.60 & 0.01 \\
\hline \multirow[t]{3}{*}{${ }^{7} \mathrm{OH}$} & $15_{\beta}$ & 3.58 & 3.46 & 0.02 & 3.95 & 0.14 \\
\hline & & & $x^{2 e}$ & 17.64 & & 6.73 \\
\hline & & & $(\sigma)^{e}$ & $(0.74)$ & & $(0.46)$ \\
\hline
\end{tabular}

${ }^{a}$ Hydrogen nucleus.

b Internuclear distance in $\AA$ computed from NOESY crosspeaks using Equations (1) and (2) (green indicates distances to the bound water molecule).

${ }^{c}$ Predicted estimates for internuclear distances using AM1 computations.

${ }^{d}$ Mean deviation squared.

e Chi squared based on 33 distances in $\AA^{2}$, and $s$ is the standard deviation in $\AA$ (red and blue highlights the largest contributor to the chi squared of boat and chair conformations, respectively).

prominent $\mathrm{CP}$ are labeled, and used to compute exchange rates and internuclear distances, which are shown in Table 2. The heteronuclear $2 \mathrm{D}$ experiments are not shown. The assignment corresponds closely to previous reports (Savard et al., 1987; Nagy et al., 2005) with some notable exceptions described below.

The assignment of $4_{\alpha}$ and $4_{\beta}$ is now reversed, where the chemical shift of the former is smaller than the latter (Table 1). This was confirmed by NOESY, where a strong cross-peak between $4_{\beta}$ and 11 is observed and that between $4_{\beta}$ and 14 is weak, which stands in contrast to the strong cross-peak $4_{\alpha}$ and 14 and that between $4_{\alpha}$ and 11 being weak. Furthermore, the crosspeak between 3 and $4_{\beta}$ is much stronger than the 1 to $4_{\alpha}$, and those from both $15_{\alpha}$ and $15_{\beta}$ to $4_{\beta}$ are much stronger than those to $4_{\alpha}$. This reassignment clearly makes it easier to appreciate the relative order in the chemical shifts where $4_{\beta}$ is larger than $4_{\alpha}$, which is consistent with $4_{\beta}$ being eclipsed by the hydroxyl oxygen on $\mathrm{C}_{3}$ (see Figure $3 \mathrm{~A}$ ). Correspondingly $4_{\alpha}$ eclipses 3 as indicated by the vicinal coupling of $10.98 \mathrm{~Hz}$, which could be easily confused with a trans vicinal coupling causing $4_{\alpha}$ and $4_{\beta}$ to be interchanged.

The assignments of the protons on the epoxy ring were reversed with respect to previous reports (Savard and Blackwell, 1994), where $13_{\alpha}$, at $3.195 \mathrm{ppm}$, has a significant cross-peak with 14 , while $13_{\beta}$, at $3.121 \mathrm{ppm}$, has a prominent cross-peak with 2 . Additionally, the larger cross-peak between 7 and $13_{\alpha}$ compared with 7 and $13_{\beta}$ further supports this assignment. Hence, the larger chemical shift of $13_{\alpha}$ compared with $13_{\beta}$ is due to its proximity to $15 \mathrm{OH}$.

The methylene protons $15_{\alpha}$ and $15_{\beta}$ are not easy to assign; however, NOESY CP provide the most convincing evidence that $15_{\alpha}$ is closer to 14 , while $15_{\beta}$ is closer to 11 . Thus, $15_{\alpha}$ nearly eclipses $C_{5}$, while similarly $15_{\beta}$ is almost eclipses $C_{11}$ and thus is oriented underneath the $\mathrm{B}$ ring, placing $15 \mathrm{OH}$ in the correct orientation to undergo $\mathrm{H}$-bonding to $7 \mathrm{OH}$. The larger chemical shift of $15_{\alpha}$ can be ascribed to its closer proximity to $7_{\mathrm{OH}}$. This indicates a preference for the gauche (with a dihedral angle $\mathrm{C}_{7}$ $\mathrm{C}_{6}-\mathrm{C}_{15}-\mathrm{O}_{15}=330^{\circ}$ ) rotamer, which is stabilized by transient H-bonding to $7 \mathrm{OH}$.

The shifts and couplings involving of the hydroxyl protons went previously unreported presumably due to being obscured by chemical exchange broadening with excess free water in the solvent. To illustrate the loss of resolution in those signals, Figure 4 compares the spectra for DON prepared with $\mathrm{CDCl}_{3}$ that was either dried or not dried. The high resolution achieved in the $\mathrm{OH}$ signals of the dried sample indicates that very slow exchange takes place with water. Line broadening in the wet sample suggests faster exchange; however, $7_{\mathrm{OH}}$ remains relatively narrow. The EXSY cross-peak intensities give exchange rates in the dry sample for $7 \mathrm{OH}$ is $0.04 \mathrm{~s}^{-1}$ while those for $15 \mathrm{OH}$ and $3 \mathrm{OH}$ are $0.12 \mathrm{~s}^{-1}$ suggesting that strong $\mathrm{H}$-bonding between $7 \mathrm{OH}$ and the carbonyl oxygen hinders water exchange.

The natural line width of the water and $\mathrm{OH}$ signal in the dry sample are below $0.2 \mathrm{~Hz}$ as their $\mathrm{T}_{2} \mathrm{~s}$ occur near $1.5 \mathrm{~s}$. Consequently, the effect of chemical exchange on the $\mathrm{OH}$ chemical shifts is negligible and thus they reflect the true shift of the $\mathrm{OH}$ environment. The $\mathrm{OH}$ shifts in the dry sample support preferential $\mathrm{H}$-bonding to $7 \mathrm{OH}$ as its shift is much larger than those of $15 \mathrm{OH}$ and $3 \mathrm{OH}$.

The water peak contains only one component in approximately equal stoichiometric proportions to DON. 

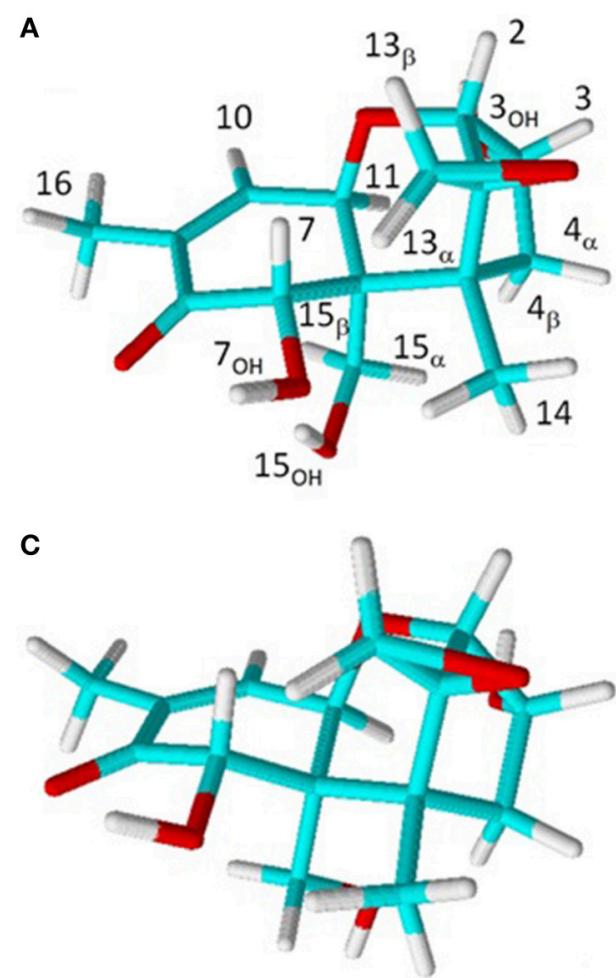

B

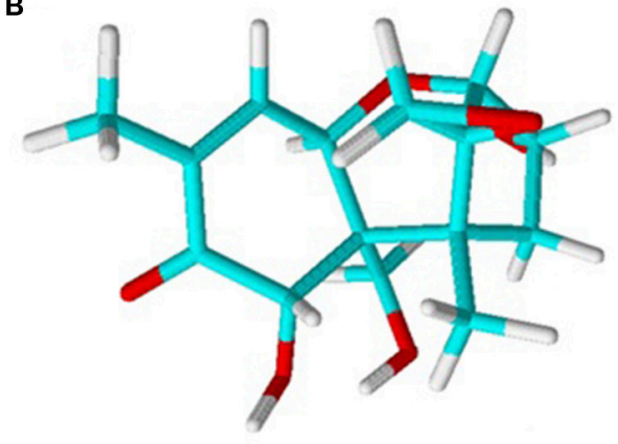

FIGURE 3 | Predicted structure of DON in (A) $\mathrm{CDCl}_{3}$ chair, (B) $\mathrm{CDCl}_{3}$ boat, and (C) DMSO- $\mathrm{d}_{6}$ chair B-ring conformations.

The signal is extremely narrow lacking any significant fine structure, indicating that it has significant mobility. In an attempt to remove water bound to DON, a sample was prepared in dried solvent where molecular sieves were added over a period of $72 \mathrm{~h}$. There was an initial slight decrease in the ratio of the water to DON, after which, the ratio remained constant with time, and the number of sieves added. The stoichiometric ratio of water to DON converged to $1: 1$, meaning that one water molecule is very strongly bound to each DON molecule.

The ${ }^{13} \mathrm{C}$ signals were assigned using HSQC and HMBC. Table 3 shows the ${ }^{13} \mathrm{C}$ assignment for $\mathrm{CDCl}_{3}$ along with all the diagnostic heteronuclear CP. All the ${ }^{13} \mathrm{C}$ chemical shifts are summarized in Table 4 and are reported with respect to TMS in all 5 solvents. The ${ }^{13} \mathrm{C}$ chemical shift assignment in $\mathrm{CDCl}_{3}$ is the same as previously reported. Additional structural observations can be made from when they are compared between the different solvents.

The internuclear distances from the NOESY spectra in $\mathrm{CDCl}_{3}$ are compared with those from structures modeled with a boat and chair configuration of the $\mathrm{B}$ ring (Figures $\mathbf{3 A}, \mathbf{B}$ ). The results are shown in Table 2. The $c^{2}$ between the experimental values and the boat configuration is $17.6 \AA^{2}$, while that with the chair configuration is $6.7 \AA^{2}$, indicating a preference for the chair form. If one were to drop internuclear distances involving any mobile nuclei (i.e., $\mathrm{OH}$, sidechain and $\mathrm{CH}_{3}$ signals) from consideration, $c^{2}$ would dramatically decrease to $11.8 \AA^{2}$ for the boat and 2.1 $\AA^{2}$ for the chair form. This significantly increases the confidence level in the match of the remaining 18 internuclear distance measurements to the chair form with a standard deviation of 0.35 $\AA$ as compared with the boat form at $0.83 \AA$.

\section{Full Spectral Assignment of DON in DMSO-d 6}

The spectrum in DMSO- $\mathrm{d}_{6}$ is shown in Figure 5 along with its simulation. Figure $\mathbf{6}$ shows the corresponding NOESY spectrum. The spectral parameters obtained by simulation and fitting to the experimental spectrum are given in Tables 5, 6 for all five solvents.

The assignment of the ${ }^{1} \mathrm{H}$ spectrum also departs from previous work concerning the methylene protons at $\mathrm{C}_{4}$ and $\mathrm{C}_{15}$. The hydroxyl resonances have been previously reported and are consistent with our findings. As in $\mathrm{CDCl}_{3}, 4_{\alpha}$, and $4_{\beta}$ are reversed with respect to previous reports (Savard and Blackwell, 1994), where the former has the lower shift, and the vicinal coupling between the $4_{\alpha}$ and 3 indicates they are eclipsed. In addition, the chemical shift of $4_{\alpha}$ decreases, while $4_{\beta}$ increases significantly between $\mathrm{CDCl}_{3}$ and DMSO-d $\mathrm{d}_{6}$. The assignments of $13_{\alpha}$ and $13_{\beta}$ is the same as in Savard et al. (1987), hence reversed with respect to $\mathrm{CDCl}_{3}$, where the shift of $13_{\alpha}$ decreases sufficiently to be lower than $13_{\beta}$ which is less sensitive to the change in solvent environment. The assignment of $13_{\alpha}$ and $13_{\beta}$ were verified by NOESY CP between $13_{\alpha}$ and 14 and between $13_{\beta}$ and 2 , respectively. Both $15_{\alpha}$ and $15_{\beta}$ decrease by similar amounts, although their absolute assignment is difficult to verify by NOESY as they both have CP with 14,11 , and $3 \mathrm{OH}$. However, $15_{\alpha}$ is the only one to have a cross-peak with $4_{\beta}$. 

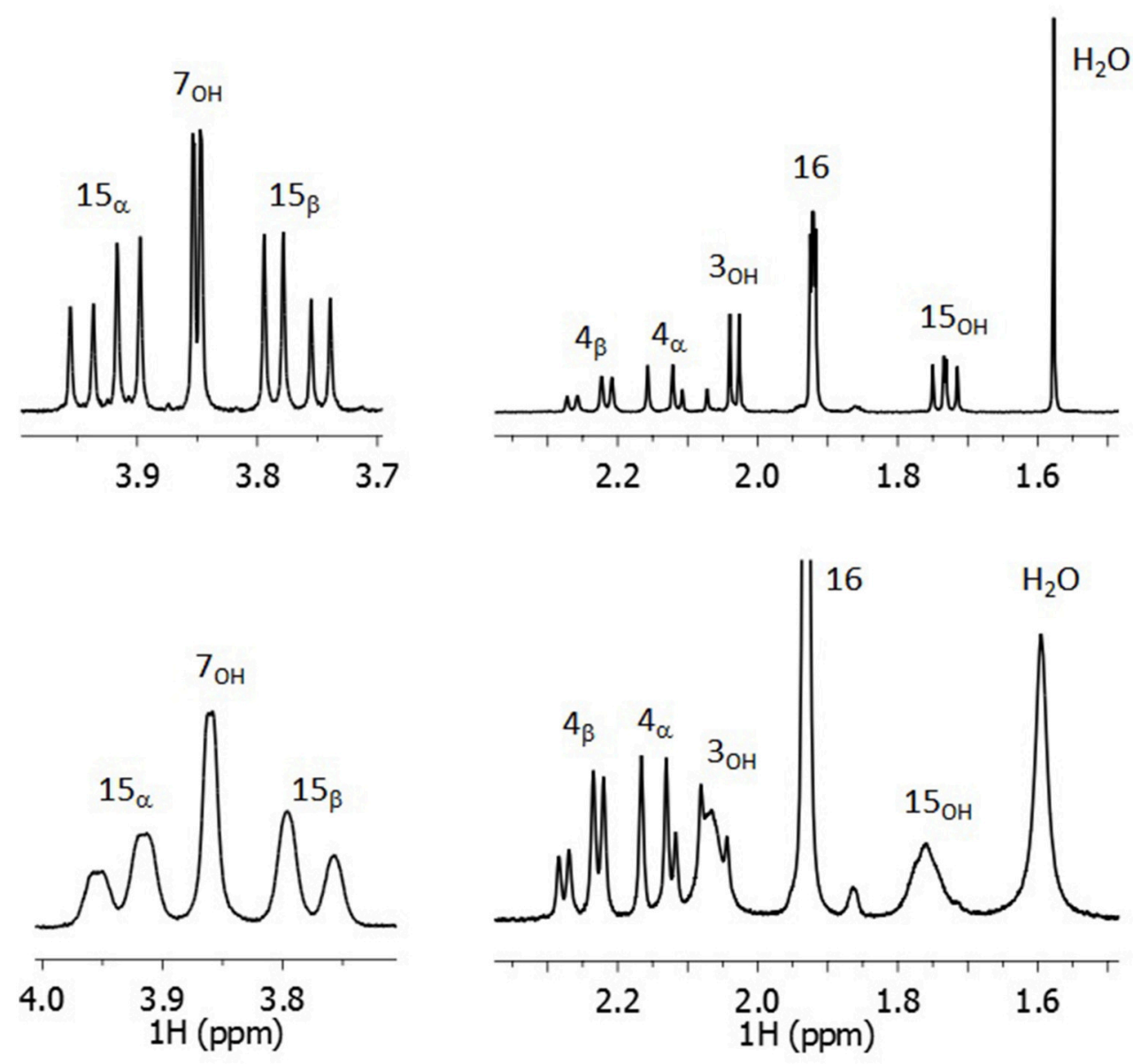

FIGURE 4 | Expansions of $\mathrm{OH}$ regions of the $300 \mathrm{MHz}^{1} \mathrm{H}$ spectrum of DON in dried (Top) and wet (Bottom) $\mathrm{CDCl}_{3}$.

Other notable trends in ${ }^{1} \mathrm{H}$ shifts changes from $\mathrm{CDCl}_{3}$ to DMSO- $\mathrm{d}_{6}$ are that all the shifts corresponding to the position on the C-ring namely 2,3 , and $4_{\alpha}$ decrease, and similarly 7,14 , and 16 decrease while 11 increases. Most of the changes in the chemical shifts can be reconciled by the reorientation of $15_{\mathrm{OH}}$ to favor the trans rotamer with respect to $\mathrm{C}_{6}$, as shown in Figure 3C. The $15_{\mathrm{OH}}$ now situated under the $\mathrm{B}$-ring oriented toward the $\mathrm{C}$ ring side. This increases the distances from $15_{\mathrm{OH}}$ to $4_{\alpha}, 7,14$, and 16 hence significantly decreasing their shifts, while decreasing the distances to $4_{\beta}$ and 11 hence increasing their shifts.

Again the slow water exchange allows $\mathrm{OH}$ shifts to be interpreted. In DMSO- $\mathrm{d}_{6}$ the chemical shift of $7_{\mathrm{OH}}$ increases the least by $1 \mathrm{ppm}$, while $15_{\mathrm{OH}}$ and $3 \mathrm{OH}$ increase much more dramatically by approximately $3 \mathrm{ppm}$ each. This can only occur if significant new $\mathrm{H}$-bonding interactions take place involving $15_{\mathrm{OH}}$ and $3 \mathrm{OH}$. In response to $15_{\mathrm{OH}}$ being sequestered $7 \mathrm{OH}$ is free to interact more strongly with the carbonyl oxygen as indicated by ${ }^{3} \mathrm{~J}_{7,7 \mathrm{OH}}$ changing from 2 to $4 \mathrm{~Hz}$ between $\mathrm{CDCl}_{3}$ and DMSO- $\mathrm{d}_{6}$.

Resolution enhancement of the water signal indicates that there are two distinct water signals. One component has a splitting pattern that resembles a doublet of triplets with a linewidth of $0.3 \mathrm{~Hz}$ (Figure 7). This is actually an AMNX spin system, where $\mathrm{A}$ and $\mathrm{X}$ are $15_{\mathrm{OH}}$ and $3 \mathrm{OH}$, and the water protons $\mathrm{M}$ and $\mathrm{N}$ are inequivalent by $0.013 \mathrm{ppm}$. The coupling constants are ${ }^{2} \mathrm{~J}_{\mathrm{MN}}=-7.8 \mathrm{~Hz}\left({ }^{2} \mathrm{~J}_{\mathrm{HH}}\right.$ is estimated from HOD in deuterium exchange study on $\mathrm{T} 2$-toxin in $\mathrm{CDCl}_{3}$ (Chaudhary et al., 2011), and the outer lines of the $\mathrm{MN}$ pattern have $1.3 \%$ intensity of inner lines and thus are lost in the noise), ${ }^{6} \mathrm{~J}_{\mathrm{AX}}=0 \mathrm{~Hz}$, and ${ }^{2} \mathrm{~J}_{\mathrm{AM}}={ }^{2} \mathrm{~J}_{\mathrm{NX}}$ and ${ }^{4} \mathrm{~J}_{\mathrm{AN}}={ }^{4} \mathrm{~J}_{\mathrm{MX}}$ each ranging from -0.20 to $-0.40 \mathrm{~Hz}$. Such a coupling pattern is consistent with an immobile bridging water species, between $3 \mathrm{OH}_{\mathrm{OH}}$ and $15_{\mathrm{OH}}$, spanning the mouth of a "binding pocket." When considering the B- and Crings together as a seven-membered ring that is bridged by the epoxide, the "binding pocket" is the bottom of the combined ring, opposite to the epoxide bridge.

The other component of the water signal exhibits no fine structure with linewidth of $0.86 \mathrm{~Hz}$. With the water bridged (hence strained) the binding pocket retains essentially the same configuration as in $\mathrm{CDCl}_{3}$ where 3 and $4_{\alpha}$ remain staggered. The exchange rate between water and all three hydroxyl groups is effectively the same near 0.07 to $0.08 \mathrm{~s}^{-1}$, which indicates 
TABLE 3 | The assignment of the carbon chemical shifts and observed ${ }^{1} \mathrm{H}-{ }^{13} \mathrm{C}$ correlations for $\mathrm{DON}$ in $\mathrm{CDCl}_{3}$.

\begin{tabular}{llll}
\hline $\mathbf{1 3} \mathbf{C}$ & $\boldsymbol{\delta}$ (ppm) $^{\mathbf{a}}$ & HSQC & HMBC \\
\hline 2 & 80.80 & 2 & 11 \\
3 & 69.17 & 3 & $2,3_{\mathrm{OH}}, 4_{\alpha \beta}$ \\
4 & 43.21 & $4 \alpha, 4_{\beta}$ & $2,4_{\beta}, 3_{\mathrm{OH}}$ \\
5 & 46.46 & & 14 \\
6 & 51.96 & & $3 \mathrm{OH}, 4_{\alpha \beta}, 7,14$ \\
7 & 70.39 & 7 & 7,14 \\
8 & 199.87 & & 11,16 \\
9 & 135.96 & & 11,16 \\
10 & 138.46 & 10 & 14 \\
11 & 74.53 & 11 & $2,4_{\alpha \beta}, 13_{\alpha \beta}, 14$ \\
12 & 65.61 & & \\
13 & 47.41 & $13_{\alpha}, 13_{\beta}$ & 11,16 \\
14 & 14.34 & 14 & $15_{\alpha}, 15_{\beta}$ \\
15 & 62.56 & 16 & \\
16 & 15.37 & & \\
\hline
\end{tabular}

${ }^{a}$ Measured directly from the spectrum. No statistical error available from fitting. The experimental digital resolution is $0.55 \mathrm{~Hz}$ or 0.007 .

TABLE 4 | Experimental and literature ${ }^{13} \mathrm{C}$ chemical shift data for DON in $\mathrm{CDCl}_{3}$, acetone- $\mathrm{d}_{6}$, and DMSO- $\mathrm{d}_{6}$.

\begin{tabular}{|c|c|c|c|c|c|c|}
\hline \multirow[t]{2}{*}{${ }^{13} \mathrm{C}$} & \multicolumn{2}{|c|}{$\mathrm{CDCl}_{3}$} & \multicolumn{2}{|c|}{ Acetone- $d_{6}$} & \multicolumn{2}{|c|}{ DMSO- $_{6}$} \\
\hline & Lit. $^{a}$ & Exp. & Lit. $^{a}$ & Exp. & Lit. $^{a}$ & Exp. \\
\hline 2 & 80.6 & 80.80 & 81.6 & 80.84 & 80.2 & 80.62 \\
\hline 3 & 68.6 & 69.17 & 69.3 & 68.60 & 67.8 & $68.17^{\mathrm{b}}$ \\
\hline 4 & 43.0 & 43.21 & 44.4 & 43.64 & 43.7 & 44.12 \\
\hline 5 & 47.2 & 46.46 & 46.5 & 45.79 & 45.4 & 45.75 \\
\hline 6 & 52.1 & 51.96 & 53.0 & 52.20 & 51.8 & 52.18 \\
\hline 7 & 70.2 & 70.39 & 70.6 & 69.71 & 69.3 & 69.61 \\
\hline 8 & 202.3 & 199.87 & 200.7 & 199.83 & 200.0 & 200.58 \\
\hline 9 & 135.7 & 135.96 & 135.6 & 134.68 & 134.8 & 135.18 \\
\hline 10 & 138.5 & 138.4 & 139.7 & 138.99 & 138.2 & 138.71 \\
\hline 11 & 74.4 & 74.53 & 75.4 & 74.57 & 74.5 & 74.84 \\
\hline 12 & 65.6 & 65.61 & 66.5 & 65.66 & 66.0 & 66.31 \\
\hline 13 & 46.0 & 47.41 & 47.5 & 46.66 & 46.7 & 47.11 \\
\hline 14 & 13.9 & 14.34 & 14.5 & 13.71 & 14.5 & 14.84 \\
\hline 15 & 61.4 & 62.56 & 61.5 & 60.80 & 60.1 & 60.47 \\
\hline 16 & 14.9 & 15.37 & 15.2 & 14.41 & 15.1 & 15.46 \\
\hline
\end{tabular}

${ }^{a}$ All literature data obtained from Jarvis et al. (1990).

${ }^{b}$ Blue indicates increase and red decrease in chemical shift with respect to $\mathrm{CDCl}_{3}$. No error estimates available from fitting. The experimental digital resolution is $0.55 \mathrm{~Hz}$ or $0.007 \mathrm{ppm}$.

that binding to $15_{\mathrm{OH}}$ and $3 \mathrm{OH}$ is stronger in DMSO- $\mathrm{d}_{6}$ than in $\mathrm{CDCl}_{3}$.

The ${ }^{13} \mathrm{C}$ shift changes occurring in DMSO- $\mathrm{d}_{6}$ with respect to $\mathrm{CDCl}_{3}$ are consistent with the conformation changes proposed, where $\delta_{\mathrm{C} 5}, \delta_{\mathrm{C} 7}$, and $\delta_{\mathrm{C} 15}$ decrease when $15_{\mathrm{OH}}$ moves under the binding pocket which also causes $\delta_{\mathrm{C} 4}, \delta_{12}$, and $\delta_{14}$ to increase.
The changes in $\delta_{\mathrm{C} 3}, \delta_{\mathrm{C} 4}$ and $\delta_{\mathrm{C} 12}$ are also due in part to reorientation of $3 \mathrm{OH}$.

Conformational changes were investigated further using NOESY CP in to compare cross relaxation rates $s_{11,4 \beta}$, $s_{15 \alpha, 4 \beta}, s_{13 \alpha, 7}, s_{13 \beta, 7}$, and $s_{13 \beta, 2}$ between the two solvents. The corresponding internuclear distances $r_{11,4 \beta}, r_{13 \beta, 2}, r_{13 \alpha, 7}$, and $\mathrm{r}_{13 \beta, 7}$ are consistently shorter in DMSO- $\mathrm{d}_{6}$ by at least $0.10,0.15$, 0.10 , and $0.25 \AA$. These changes indicate that water binding has caused slight changes in the binding pocket bringing $\mathrm{C}_{4}$ and $\mathrm{C}_{3}$ closer to $\mathrm{C}_{6}$ and $\mathrm{C}_{11}$, effectively increasing the degree of folding between the $\mathrm{B}$ - and $\mathrm{C}$-rings by decreasing the valence angles at $\mathrm{C}_{2}$ and $\mathrm{C}_{5}$. As a result, the epoxide ring becomes further removed from the A- and C-rings. This is corroborated by the decrease in chemical shifts of $2,3,4 \alpha$, and 7 which would experience deshielding effect of the epoxide ring less strongly. Also the reorientation of $15 \mathrm{OH}$ to underneath the binding pocket was confirmed by $\mathrm{r}_{15 \alpha, 4 \beta}$ decreasing from 2.70 to $2.19 \AA$.

Additional evidence for changes in the geometry of the Band C-rings upon water binding is seen in the changes to the scalar couplings in DMSO- $\mathrm{d}_{6}$. The dihedral angle between 2 and 3 increases, and between 3 and $4_{\alpha}$ decrease as indicated by ${ }^{3} \mathrm{~J}_{2,3}$ decreasing and ${ }^{3} \mathrm{~J}_{3,4 \alpha}$ increasing. The valence angle between $4_{\alpha}$ and $4_{\beta}$ increases and that between $C_{3}$ and $C_{5}$ decreases as indicated by ${ }^{2} \mathrm{~J}_{4 \alpha, 4 \beta}$ decreasing. Increased strain in the epoxide ring can be inferred by the increase in ${ }^{2} \mathrm{~J}_{13 \alpha, 13 \beta}$.

\section{Analysis of the ${ }^{1} \mathrm{H}$ Spectra of DON in Acetone- $d_{6}$, THF- $d_{4}$, and Methanol- $d_{4}$}

The ${ }^{1} \mathrm{H}$ chemical shift trends in the remaining solvents are consistent with the findings in DMSO- $\mathrm{d}_{6}$. The shifts of 11 and $4_{\beta}$ increase, whereas that of $4_{\alpha}$ decreases (Table 5). Even though the trends in 7,2,3, and $13_{\alpha}$ are not as extreme as in DMSO- $\mathrm{d}_{6}$, they do follow the same sense. Also, in acetone- $\mathrm{d}_{6}$ and THF- $\mathrm{d}_{4}$ the $3 \mathrm{OH}$ and $15_{\mathrm{OH}}$ shifts increase significantly by 2 ppm, which are not quite as large as in DMSO- $\mathrm{d}_{6}$. In methanol- $\mathrm{d}_{4}$ the hydroxyl signals could not be observed as they were lost to deuterium exchange with the solvent.

Only the water signal in acetone- $\mathrm{d}_{6}$ exhibited sufficient resolution such that two components could be found, corresponding to two bound water molecules; however, there were no fine structural features that indicate a bridging binding motif. Cross-relaxation measurements suggest that one of the water molecules was approximately $2.80 \AA$ away from 11 .

In all three solvents $15 \mathrm{OH}$ does favor the trans rotamer; however, not exclusively as in DMSO- $\mathrm{d}_{6}$. The remaining mobility in $15 \mathrm{OH}$ accounts for the smaller increases in the hydroxyl shifts as well as the weaker trends in $7,2,3$, and $13_{\alpha}$. The weaker bonding interaction in the binding pocket for methanol- $\mathrm{d}_{4}$ and THF- $\mathrm{d}_{4}$ is not just the result of differing solvent polarity as they also contain much more free water, where the water to DON ratio was 14 and 30 to one, respectively. Furthermore, methanol- $\mathrm{d}_{4}$ is a hydrogen bonding solvent and therefore would compete with water thereby further weakening the water binding to DON. One would expect to see the same effect in bulk water. 


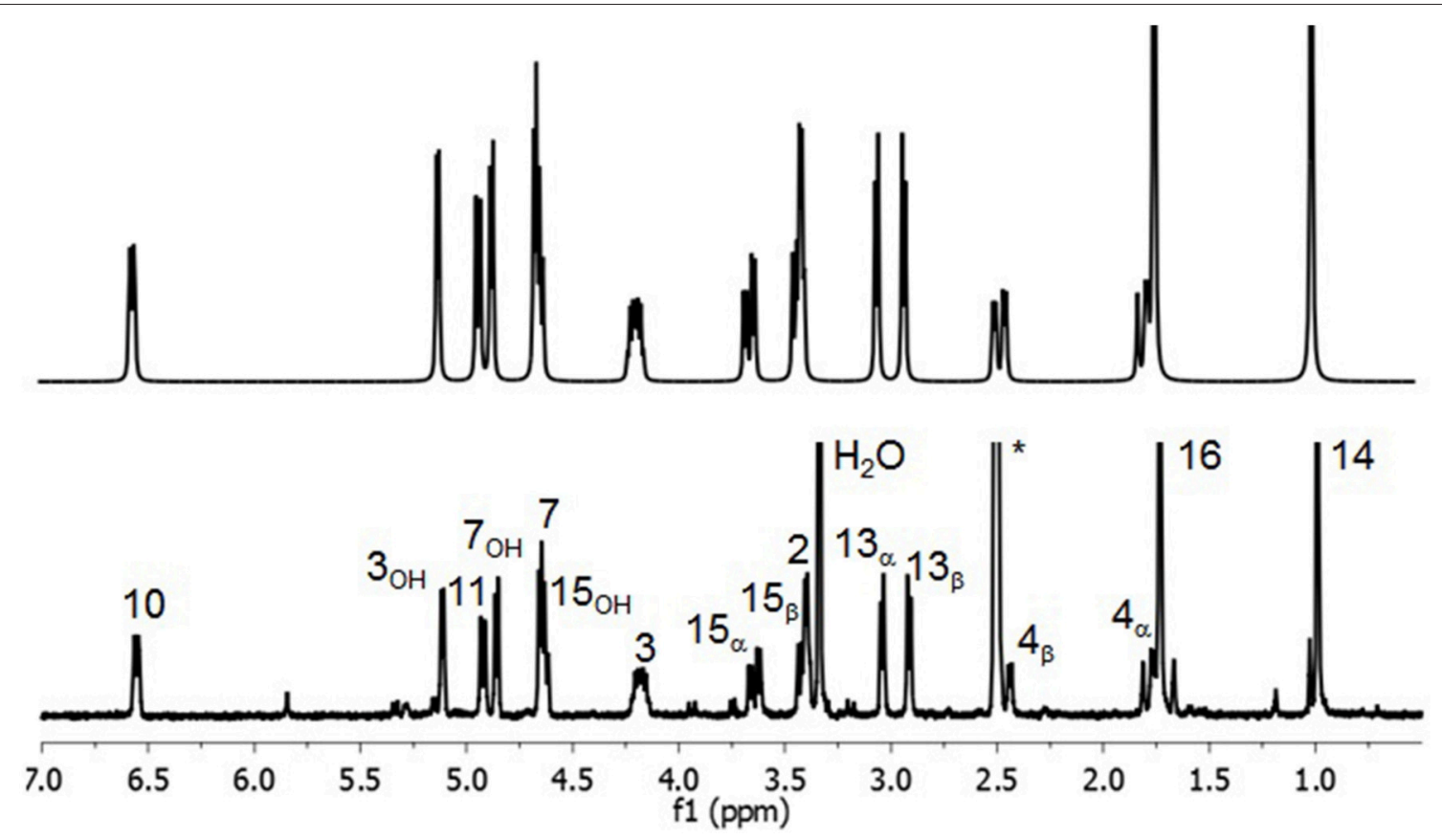

FIGURE 5 | Experimental (Bottom) and simulated (Top) $300 \mathrm{MHz}^{1} \mathrm{H}$ spectrum of DON in DMSO- $\mathrm{d}_{6}$.

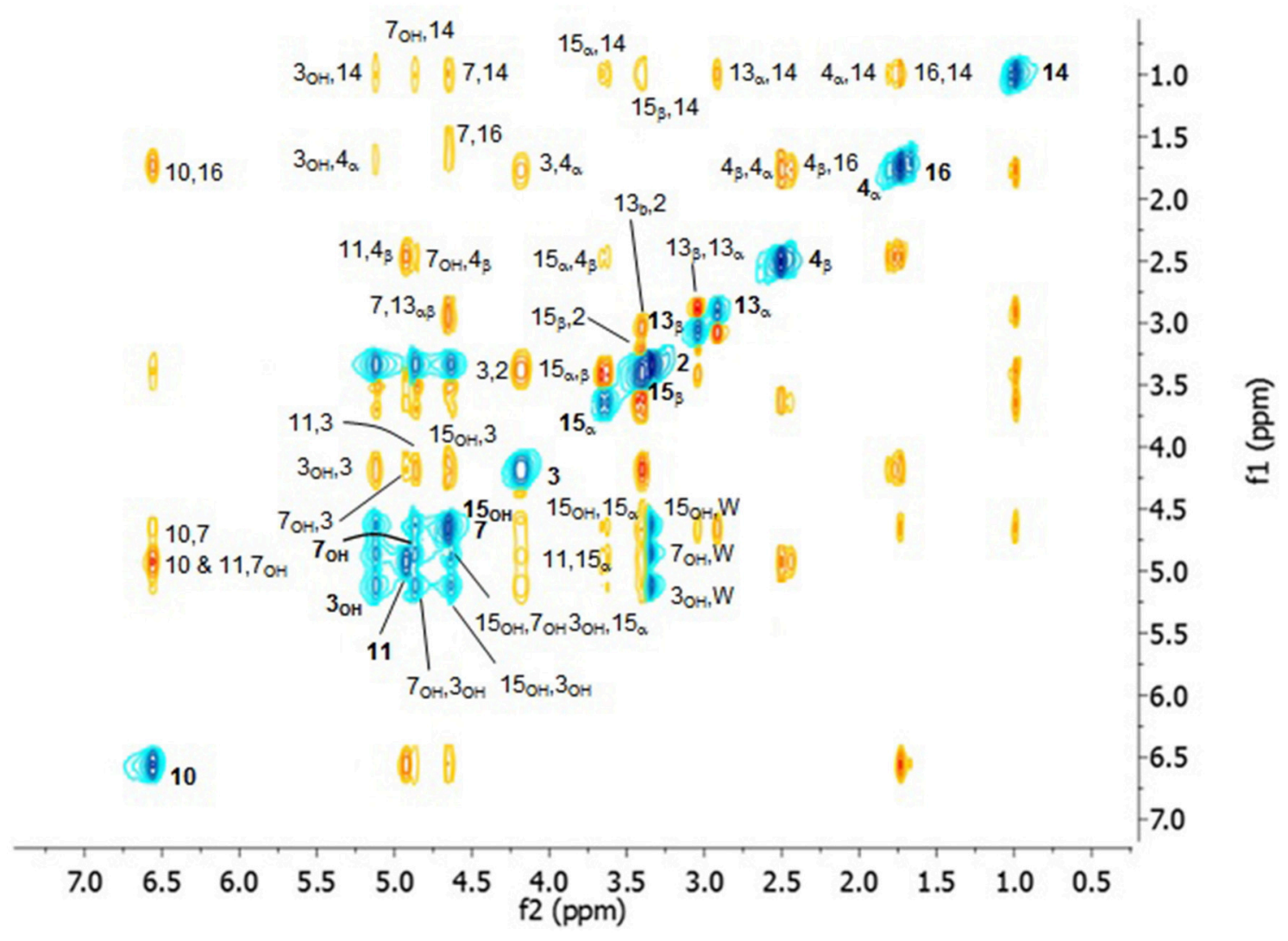

FIGURE 6 | $300 \mathrm{MHz}{ }^{1} \mathrm{H}$ NOESY of DON in DMSO-d 6 with a mixing time of $1 \mathrm{~s}$. 
TABLE 5 | The chemical shifts (ppm) and associated error $(\mathrm{Hz})$ obtained by fitting the ${ }^{1} \mathrm{H}$ spectra of DON are in the various solvents.

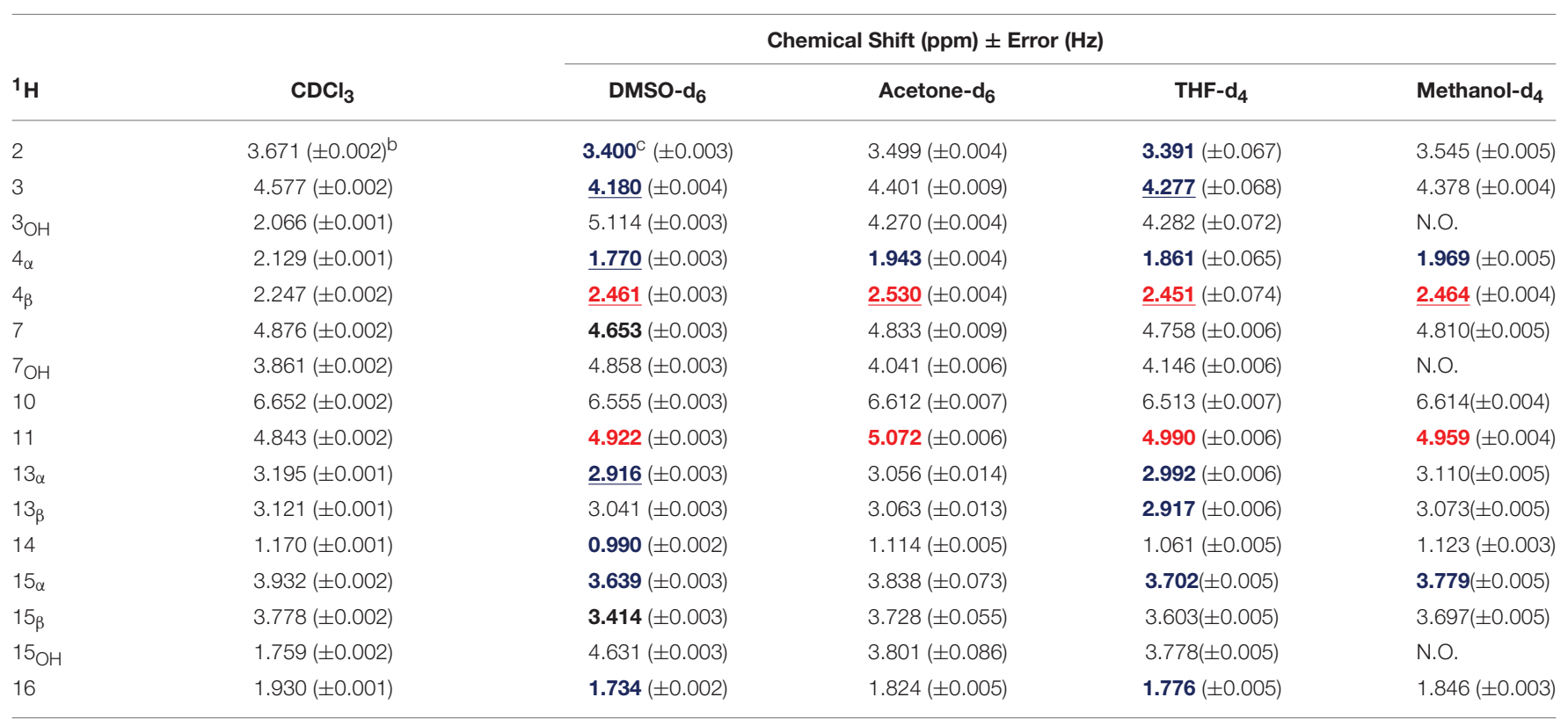

RMS $^{\mathrm{a}}$

a Typically 4200 transition were assigned in total. RMS, Root mean square deviation. The largest absolute difference was typically below $0.1 \mathrm{~Hz}$.

${ }^{b}$ The simulations give chemical shifts in $\mathrm{Hz}$ units with standard deviation of less than 0.002 to $0.1 \mathrm{~Hz}$. This amounts $5-7$ significant figures; therefore, when converting to ppm the shifts should have be recorded from 4 to 6 decimal places. In this case the errors are given in $\mathrm{Hz}$ units, as in ppm the error would be 0 up to the third decimal place.

${ }^{c}$ Red indicated increase and blue a decrease in chemical shift with respect to $\mathrm{CDCl}_{3}$. The more significant changes are underlined.

TABLE 6 | Scalar couplings $(\mathrm{Hz})$ and associated error $(\mathrm{Hz})$ obtained by fitting the ${ }^{1} \mathrm{H}$ spectra of DON in the various solvents.

\begin{tabular}{|c|c|c|c|c|c|}
\hline & $\mathrm{CDCl}_{3}$ & DMSO- $_{6}$ & Acetone- $d_{6}$ & THF-d ${ }_{4}$ & Methanol-d $d_{4}$ \\
\hline${ }^{3} \mathrm{~J}(2,3)$ & $4.940( \pm 0.003)$ & $4.121( \pm 0.006)$ & $4.407( \pm 0.007)$ & $4.583( \pm 0.113)$ & $4.428( \pm 0.008)$ \\
\hline $3 \mathrm{~J}\left(3,3_{\mathrm{OH}}\right)$ & $4.080( \pm 0.003)$ & $4.112( \pm 0.006)$ & $4.085( \pm 0.007)$ & $4.416( \pm 0.108)$ & N.O. \\
\hline${ }^{3} \mathrm{~J}\left(3,4_{\beta}\right)$ & $4.140( \pm 0.003)$ & $3.347( \pm 0.006)$ & $4.368( \pm 0.007)$ & $4.059( \pm 0.112)$ & $4.369( \pm 0.008)$ \\
\hline${ }^{2} \mathrm{~J}\left(4_{\alpha}, 4_{\beta}\right)$ & $-14.870( \pm 0.003)$ & $-14.040( \pm 0.006)$ & $-14.466( \pm 0.006)$ & $-14.479( \pm 0.101)$ & $-14.512( \pm 0.009)$ \\
\hline${ }^{4} \mathrm{~J}(10,16)$ & $-1.510( \pm 0.002)$ & $-1.511( \pm 0.007)$ & $-1.526( \pm 0.006)$ & $-1.607( \pm 0.006)$ & $-1.601( \pm 0.007)$ \\
\hline${ }^{2} \mathrm{~J}\left(13_{\alpha}, 13_{\beta}\right)$ & $4.220( \pm 0.003)$ & $4.575( \pm 0.005)$ & $4.514( \pm 0.011)$ & $4.565( \pm 0.010)$ & $5.065( \pm 0.011)$ \\
\hline $2 \mathrm{~J}\left(15_{\alpha}, 15_{\beta}\right)$ & $-12.032( \pm 0.004)$ & $-11.230( \pm 0.006)$ & $-11.961( \pm 0.120)$ & $-11.600( \pm 0.105)$ & $-11.816( \pm 0.012)$ \\
\hline${ }^{3} \mathrm{~J}\left(15_{\alpha}, 15_{\mathrm{OH}}\right)$ & $5.670( \pm 0.003)$ & $5.251( \pm 0.006)$ & $5.696( \pm 0.138)$ & $5.285( \pm 0.104)$ & N.O. \\
\hline${ }^{3} \mathrm{~J}\left(15_{\beta}, 15_{\mathrm{OH}}\right)$ & $4.820( \pm 0.003)$ & $4.739( \pm 0.005)$ & $4.819( \pm 0.094)$ & $4.767( \pm 0.107)$ & N.O. \\
\hline
\end{tabular}

\section{DISCUSSION}

\section{Water Binding in the Proposed Structure with NOESY in $\mathrm{CDCl}_{3}$ and DMSO-d 6}

Previous work in our group showed that a water molecule is bound to T-2 toxin at a 1:1 ratio (Chaudhary et al., 2011). The same was observed here for DON in both chemical environments investigated. Water binding to DON was observed through crossrelaxation between water and protons of the binding pocket. Internuclear distances in $\mathrm{CDCl}_{3}$ from water to $2,3,11,15_{\alpha}$ and $15_{\beta}$ are $2.99,2.84,3.14,2.93$, and $3.22 \AA$, respectively. This places at least one water molecule beneath the binding pocket in the vicinity of $15 \mathrm{OH}$ and $3 \mathrm{OH}$. The lack of fine structure in the high resolution water ${ }^{1} \mathrm{H}$ signal suggest significant mobility remains in the bound water and thus is unlikely to bridge $3 \mathrm{OH}$ to $15 \mathrm{OH}$.

In $\mathrm{DMSO}_{-} \mathrm{d}_{6}$ water binding involves one water molecule bridging the $3 \mathrm{OH}$ to $15_{\mathrm{OH}}$. Additional water may be bound elsewhere; however, it would be more mobile in a similar manner to what is observed in $\mathrm{CDCl}_{3}$. Unfortunately, no $\mathrm{CP}$ between 

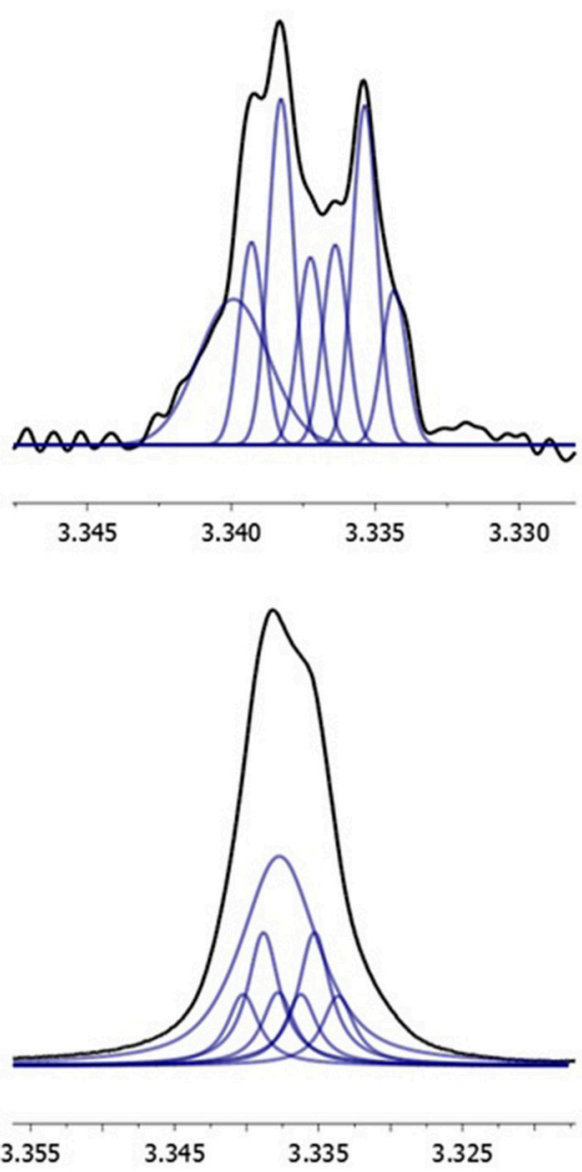

FIGURE 7 | Expansion of the water signal in the $300 \mathrm{MHz}^{1} \mathrm{H}$ spectrum of DON in DMSO-d $\mathbf{6}$. Left: Gauss-Lorenz apodization with $L B=-0.9 \mathrm{~Hz}$ and $\mathrm{GB}=0.35 \mathrm{~Hz}$. Right: No apodization. Each are deconvolved into a doublet of triplets and one singlet.

water and 2,11 , or $15_{\alpha}$ and $15_{\beta}$ could be resolved, or found to be adequately free from $t_{1}$ noise to obtain reliable distance estimates. It was possible to integrate the cross-peak with 3 giving a distance of $r_{\mathrm{W}, 3}=2.25 \AA$ which is significantly smaller than in $\mathrm{CDCl}_{3}$ and supports the bridging binding mode.

Considerable conformational variation exists amongst the trichothecenes due to differences in the pucker of the A- and B-rings. X-ray studies indicate a preference for the B-ring to adopt a chair conformation (see Scheme 2) in the crystal phase (Greenhalgh et al., 1984), although boat configurations have been observed for the macrocyclic trichothecenes (Jarvis and Mazzola, 1982; Jarvis and Wang, 1999). Until now, direct evidence for the chair configuration in solution was scarce, apart from some long range scalar coupling interactions observed between $7_{\beta}$ and 11 in some systems pointing toward the chair form for the B-ring (Greenhalgh et al., 1989). In the structure presented herein, the B-ring is shown to be in a chair configuration, and the water molecule is bound in the binding pocket in both $\mathrm{CDCl}_{3}$ and DMSO- $\mathrm{d}_{6}$ (Figure 3).
The major structural differences observed between the two environments occurred with respect to the $\mathrm{OH}$ groups, which undergo distinct internal $\mathrm{H}$-bonding and water binding patterns. In $\mathrm{CDCl}_{3}$ the $15_{\mathrm{OH}}$ has significant configurational flexibility and undergoes $\mathrm{H}$-bonding with both $7 \mathrm{OH}$ and $3 \mathrm{OH}$, although $7 \mathrm{OH}$ is primarily occupied with $\mathrm{H}$-bonding with the carbonyl oxygen at $\mathrm{C}_{8}$. In DMSO- $\mathrm{d}_{6}$, the interaction between $15_{\mathrm{OH}}$ and $7 \mathrm{OH}$ is lost, and the $15 \mathrm{OH}$ interaction with $3 \mathrm{OH}$ involves a bridging through a water molecule. This bridged interaction leads to a much stronger binding of the water in DMSO$\mathrm{d}_{6}$ as compared with $\mathrm{CDCl}_{3}$. Furthermore, water binding in DMSO- $\mathrm{d}_{6}$ leads to slight conformational changes in the $\mathrm{B}$ - and C-rings, such that the opening of the combined rings is smaller, thus accommodating the water bridging. Therefore, in non-Hbonding and low polarity environments, in the absence of free water, the configuration of the binding pocket arranges the $3 \mathrm{OH}$ and $15 \mathrm{OH}$ optimally for donation, hence they will be very reactive to nearby acceptors, such as water, basic amino acid residues, and metal cations.

\section{Comparison of DON Structures in Solution with Reported Structures of Bound Trichothecenes}

The crystal structure of DON and other trichothecenes bound to the yeast ribosome (Garreau De Loubresse et al., 2014) and to Fusarium trichothecene acetyltransferases, TRI101 (Garvey et al., 2008) and TRI3 (Garvey et al., 2009), were previously reported. In the bound crystal structures for DON (Garvey et al., 2008; Garreau De Loubresse et al., 2014) and in the solution structure in DMSO- $\mathrm{d}_{6}$ described herein, the B-ring is in the chair configuration and the $15_{\mathrm{OH}}$ group is pointing underneath the ring. In DMSO- $\mathrm{d}_{6}$, the $15 \mathrm{OH}$ is poised underneath the C-ring, whereas when bound in TRI101 it is underneath the A-ring. In the ribosome-bound crystal structure it is unclear whether it is pointing inwards toward the A- or C-ring. By contrast, in $\mathrm{CDCl}_{3}$, the $15_{\mathrm{OH}}$ of $\mathrm{DON}$ is pointing outwards from the molecule. Interestingly, this is similar to the crystal structures of the ribosome-bound and the TRI101-bound T2 toxin (Garvey et al., 2008; Garreau De Loubresse et al., 2014), where the $15_{\mathrm{OAc}}$ is unambiguously pointing outwards. Furthermore, a water molecule was observed in the vicinity of the binding pocket in the TRI101-DON and TRI3-15-decalonectrin interactions (Garvey et al., 2008, 2009), in approximately the same distance as observed for DON herein. Furthermore, in the TRI101-DON interact, a strong donor-acceptor interaction was observed between the $3 \mathrm{OH}$ and His-156 (Garvey et al., 2008).

Based on these structural insights, we propose the following mechanism of inhibition of protein synthesis. The epoxide ring, known to be essential for toxicity, was not reported to have direct interactions with ribosomal components in the crystal structure presented by Garreau De Loubresse et al. (2014). The specific nature of the epoxide ring making it essential for toxicity is unclear; however, it stands to reason that the epoxide holds the binding pocket in an ideal configuration to bring $3 \mathrm{OH}$ and $15 \mathrm{OH}$ in close proximity. The NMR structures presented here show 

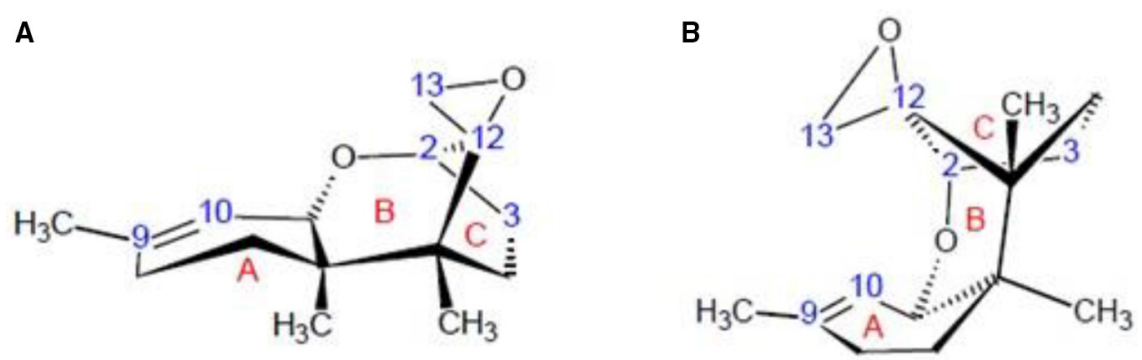

SCHEME 2 | Three-dimensional stereochemistry of the trichothecene core when (A) the A-ring is in a half-chair, and the B-ring in a chair conformation; and $(B)$ the A-ring is a half-chair, and the B-ring in a boat conformation.

that $3 \mathrm{OH}$ and $15 \mathrm{OH}$ bind to a water molecule in various ways depending on the nature of the solvent. Thus, we hypothesize that in a cellular environment, where free water is limited, the $15_{\mathrm{OH}}$ and $3 \mathrm{OH}$ of DON interacts with a magnesium ion in the A-site in the PTC (which is aligned with the normal vector to the plane of the opening of binding pocket) thereby disrupting its activity by changing the local conformation of the PTC. It should be noted that the resolution of the toxin in the ribosome was not sufficient enough to determine whether or not any water was included in the binding. In the event that water is present, it is also possible that the water itself, held in place through the bridging interaction, interacts with the magnesium ion. If the magnesium ion were to be sequestered in either capacity, the local conformation in the PTC would be disrupted; hence, the peptidyl transferase activity would be inhibited.

\section{Implications of Water Binding on the Toxicity Of DON and Related Trichothecenes}

The work presented herein provides new high resolution structural and dynamic information for the trichothecene toxin DON. Our results support previous structural works, but also give new insights with respect to the role of water. Of note, is the detailed hydrogen bonding interaction with water which revealed a bridging between $3 \mathrm{OH}$ and $15 \mathrm{OH}$. This binding between water and DON is incredibly strong with exchange rates of 0.04$0.12 \mathrm{~s}^{-1}$, which represents a Gibbs energy on the order of 77$81 \mathrm{~kJ} \mathrm{~mol}^{-1}$. In a previous study (Chaudhary et al., 2011), we reported water binding with T-2 toxin where the $3 \mathrm{OH}$ was also shown to be important; however, in this case, the functional group at $\mathrm{C}_{15}$ is substituted with an acetyl group in T-2 toxin, which prevents the formation of the water bridge observed here for DON.

The nature of the water binding is likely very important for toxicity, and the strength of this interaction with the molecule may explain differences in toxicity. For example, our work shows that $3 \mathrm{OH}$ plays an important role in water binding, meanwhile substitution at the $3 \mathrm{OH}$ in trichothecenes, such as acetylation or glycosylation, has been shown to reduce or eliminate toxicity (Alexander et al., 1999; Poppenberger et al., 2003; McCormick, 2009). It is possible that these modifications at $C_{3}$ increase the number of possible binding modes which are non-optimal for donor-acceptor interactions of the binding pocket with its immediate surroundings, thereby reducing its ability to effectively bind magnesium.

We hypothesize that the role of the epoxide ring in toxicity is in stabilizing the structure of the binding pocket for interactions with water and/or relevant molecules in its vicinity, and that differences in toxicity are related to (a) the reactivity of the binding pocket, which is based on substitution patterns on the trichothecene core, and (b) the orientation of the binding pocket with respect to the magnesium ion in the A-site of the PTC. This hypothesis outlines directions of future inquiries currently under investigation, such as effects of substitutions on water binding, the role of the epoxide ring on water binding, direct donor-acceptor interactions of these toxins with metal centers. The knowledge to be obtained from these studies can be exploited to initiate and/or support the development of detoxification strategies. Strategies to modify the $\mathrm{C}_{3}$ have previously been proposed to reduce the impacts of trichothecene contamination of grain using transgenic approaches (Muhitch et al., 2000; Alexander, 2008; Shin et al., 2012). The work herein provides the first insights as to why substitutions at $\mathrm{C}_{3}$ reduce toxicity, namely the role of $3 \mathrm{OH}$ in water binding. Further analysis of this interaction may lead alternative strategies to disrupt the interaction with water and could therefore be used in trichothecene remediation from contaminated grains.

\section{AUTHOR CONTRIBUTIONS}

NF contributed to roughly half of the writing of this manuscript and brought her perspective as molecular biologist/biochemist to the study to put things into context with FHB research, bringing biological insights, and discussion from the data that was generated. RS was a M.Sc. student working under the cosupervision of $\mathrm{PH}$ and FE. She conducted the first round of NMR experiments and provided some ideas for background discussion. $\mathrm{DK}$ is a B.Sc. student who was working under the supervision of $\mathrm{PH}$. He conducted the second round of NMR experiments and provided the majority of the data used for this manuscript. $\mathrm{PH}$ contributed to roughly half of the writing of this manuscript, provided detailed analysis of the data, prepared the figures and 
tables. He provided financial contributions to the project and expertise in chemistry and NMR. FE provided the main source of financial contributions to the project, and contributed expertise in $\mathrm{FHB}$.

\section{FUNDING}

This research was funded by Agriculture and Agri-Food Canada (AAFC) research grants awarded to FE and NSERC grants awarded to $\mathrm{PH}$.

\section{REFERENCES}

Alexander, N. J. (2008). The TRI101 story: engineering wheat and barley to resist Fusarium head blight. World Mycotoxin J. 1, 31-37. doi: 10.3920/WMJ2008.x004

Alexander, N. J., McCormick, S. P., and Ziegenhorn, S. L. (1999). Phytotoxicity of selected trichothecenes using Chlamydomonas reinhardtii as a model system. Nat. Toxins 7, 265-269.

Boutigny, A. L., Richard, F. F., and Barreau, C. (2008). Natural mechanisms for cereal resistance to the accumulation of Fusarium trichothecenes. Eur. J. Plant Pathol. 121, 411-423. doi: 10.1007/s10658-007-9266-x

Bullerman, L. B., and Bianchini, A. (2007). Stability of mycotoxins during food processing. Int. J. Food Microbiol. 119, 140-146. doi: 10.1016/j.ijfoodmicro.2007.07.035

Chaudhary, P., Shank, R. A., Montina, T., Goettel, J. T., Foroud, N. A., Hazendonk, P., et al. (2011). Hydrogen-bonding interactions in T-2 toxin studied using solution and solid-state NMR. Toxins 3, 1310-1331. doi: 10.3390/toxins3101310

Cole, R. J., and Cox, R. H. (1981). "The trichothecenes," in Handbook of Toxic Fungal Metabolites, ed C. R. C. Rh (Toronto, ON: Academic Press), 152-263.

Desjardins, A. E., McCormick, S. P., and Appell, M. (2007). Structure-activity relationships of trichothecene toxins in an Arabidopsis thaliana leaf assay. J. Agric. Food Chem. 55, 6487-6492. doi: 10.1021/jf0709193

Dill-Macky, R., and Jones, R. K. (2000). The effect of previous crop residues and tillage on fusarium head blight of wheat. Plant Dis. 84, 71-76. doi: 10.1094/PDIS.2000.84.1.71

Ehrlich, K. C., and Daigle, K. W. (1987). Protein synthesis inhibition by 8 oxo-12,13-epoxytrichothecenes. Biochim. Biophys. Acta 923, 206-213. doi: 10.1016/0304-4165(87)90005-5

Foroud, N. A., Chatterton, S., Reid, L. M., Turkington, T. K., Tittlemier, S. A., and Gräfenhan, T. (2014). "Fusarium diseases of Canadian grain crops: impact and disease management strategies," in Future Challenges in Crop Protection Against Fungal Pathogens, eds A. Goyal and C. Manoharachary (New York, NY: Springer), 267-316.

Foroud, N. A., and Eudes, F. (2009). Trichothecenes in cereal grains. Int. J. Mol. Sci. 10, 147-173. doi: 10.3390/ijms10010147

Fragaki, G., Stefanaki, I., Dais, P., and Mikros, E. (2008). Conformational properties of the macrocyclic trichothecene mycotoxin verrucarin $\mathrm{A}$ in solution. Mag. Res. Chem. 46, 1102-1111. doi: 10.1002/mrc.2298

Fuchs, E., Binder, E. M., Heidler, D., and Krska, R. (2002). Structural characterization of metabolites after the microbial degradation of type A trichothecenes by the bacterial strain BBSH 797. Food Addit. Contam. 19, 379-386. doi: 10.1080/02652030110091154

Gardiner, S. A., Boddu, J., Berthiller, F., Hametner, C., Stupar, R. M., Adam, G., et al. (2010). Transcriptome analysis of the barley-deoxynivalenol interaction: evidence for a role of glutathione in deoxynivalenol detoxification. Mol. Plant Microbe Interact. 23, 962-976. doi: 10.1094/MPMI-23-7-0962

Garreau de Loubresse, N., Prokhorova, I., Holtkamp, W., Rodnina, M. V., Yusupova, G., and Yusupov, M. (2014). Structural basis for the inhibition of the eukaryotic ribosome. Nature 513, 517-522. doi: 10.1038/nature13737

\section{ACKNOWLEDGMENTS}

This research was funded by NSERC and Agriculture and AgriFood Canada (AAFC). Special thanks to Dr. Barbara Blackwell from AAFC-Ottawa for providing the DON sample and for her insights in NMR of trichothecenes, and the NMR facility manager Tony Montina at the University of Lethbridge for his assistance. From the Department of Chemistry and Biochemistry at University of Lethbridge we thank Dr. Peter Dibble for his valuable input and Dr. Nehal Thakor for his insights and critical reading of this manuscript.

Garvey, G. S., McCormick, S. P., Alexander, N. J., and Rayment, I. (2009) Structural and functional characterization of TRI3 trichothecene 15-Oacetyltransferase from Fusarium sporotrichioides. Protein Sci. 18, 747-761. doi: $10.1002 /$ pro. 80

Garvey, G. S., McCormick, S. P., and Rayment, I. (2008). Structural and functional characterization of the TRI101 trichothecene 3-O-acetyltransferase from Fusarium sporotrichioides and Fusarium graminearum. J. Biol. Chem. 283, 1660-1669. doi: 10.1074/jbc.M705752200

Gilly, M., Benson, N. R., and Pellegrini, M. (1985). Affinity labeling the ribosome with eukaryotic-specific antibiotics: (bromoacetyl)trichodermin. Biochemistry 24, 5787-5792. doi: 10.1021/bi00342a015

Greenhalgh, R., Blackwell, B. A., and Savard, M. E. (1989). The NMR spectra of trichothecenes and related fungal metabolites. Tetrahedron 45, 2373-2383. doi: 10.1016/S0040-4020(01)83437-2

Greenhalgh, R., Hanson, A. W., Miller, J. D., and Taylor, A. (1984). Production and X-ray crystal structure of 3-acetoxy-7,15-dihydroxy-12,13-epoxytrichothec9-en-8-one. J. Agric. Food Chem. 32, 945-948. doi: 10.1021/jf0012 $4 \mathrm{a} 060$

Jarvis, B. B., Mazzocchi, D. B., Ammon, H. L., Mazzola, E. P., Flippen-Anderson, J. L., Gilardi, R. D., et al. (1990). Conformational effects in trichothecenes: structures of 15-hydroxy C4 and C8 ketones. J. Org. Chem. 55, 3660-3662. doi: 10.1021/jo00298a053

Jarvis, B. B., and Mazzola, E. P. (1982). Macrocyclic and other novel trichothecenes: their structure, synthesis, and biological significance. Acc. Chem. Res. 15, 388-395. doi: 10.1021/ar00084a002

Jarvis, B. B., and Wang, S. (1999). Stereochemistry of the roridins. Diastereomers of roridin E. J. Nat. Prod. 62, 1284-1289. doi: 10.1021/np990272j

Kluger, B., Bueschl, C., Lemmens, M., Berthiller, F., Häubl, G., Jaunecker, G., et al. (2013). Stable isotopic labelling-assisted untargeted metabolic profiling reveals novel conjugates of the mycotoxin deoxynivalenol in wheat. Anal. Bioanal. Chem. 405, 5031-5036. doi: 10.1007/s00216-0126483-8

Krupinsky, J. M., Bailey, K. L., Mcmullen, M. P., Gossen, B. D., and Turkington, T. K. (2002). Managing plant disease risk in diversified cropping systems. Agronomy J. 94, 198-209. doi: 10.2134/agronj2002.1980

Marat, K. (2009). SpinWorks 3.1.6. (Producer). Winnipeg: University of Manitoba.

McCormick, S. P. (2009). "Phytotoxicity of trichothecenes," in Mycotoxin Prevention and Control in Agriculture, eds M. Appell, D. F. Kendra, and M. W. Trucksess (Washington, DC: American Chemical Society), 143-155.

McCormick, S. P., Stanley, A. M., Stover, N. A., and Alexander, N. J. (2011). Trichothecenes: from simple to complex mycotoxins. Toxins 3, 802-814. doi: 10.3390/toxins3070802

McLaughlin, C. S., Vaughn, M. H., Campbell, J. M., Wei, C. M., and Stafford, M. E. (1977). "Inhibition of protein synthesis by trichothecenes," in Mycotoxins in Human and Health, eds J. V. Rodricks, C. W. Hesseltine, and M. A. Mehlman (Illenois, IL: Pathotox Publishers), 263-275.

McMullen, M., Bergstrom, G., De Wolf, E., Dill-Macky, R., Hershman, D., Shaner, G., et al. (2012). A unified effort to fight an enemy of wheat and barley: fusarium head blight. Plant Dis. 96, 1712-1728. doi: 10.1094/PDIS-03-120291-FE 
McMullen, M., Halley, S., Schatz, B., Meyer, S., Jordahl, J., and Ransom, J. (2008). Integrated strategies for Fusarium head blight management in the United States. Cereal Res. Commun. 36, 563-568. doi: 10.1556/CRC.36.2008.Suppl.B.45

Meskauskas, A., and Dinman, J. D. (2008). Ribosomal protein L3 functions as a rocker switch to aid in coordinating of large subunit-associated functions in eukaryotes and Archaea. Nucleic Acids Res. 36, 6175-6186. doi: 10.1093/nar/gkn642

Mitterbauer, R., Poppenberger, B., Raditschnig, A., Lucyshyn, D., Lemmens, M., Glössl, J., et al. (2004). Toxin-dependent utilization of engineered ribosomal protein L3 limits trichothecene resistance in transgenic plants. Plant Biotechnol. J. 2, 329-340. doi: 10.1111/j.1467-7652.2004.00075.x

Muhitch, M. J., McCormick, S. P., Alexander, N. J., and Hohn, T. M. (2000). Transgenic expression of the TRI101 or PDR5 gene increases resistance of tobacco to the phytotoxic effects of the trichothecene 4,15-diacetoxyscirpenol. Plant Sci. 157, 201-207. doi: 10.1016/S0168-9452(00)00282-X

Nagy, C. M., Fejer, S. N., Berek, L., Molnar, J., and Viskolcz, B. (2005). Hydrogen bondings in deoxynivalenol (DON) conformations-a density functional study. J. Mol. Struct.-THEOCHEM. 726, 55-59. doi: 10.1016/j.theochem.2005. 02.079

Pestka, J. (2010). Toxicological mechanisms and potential health effects of deoxynivalenol and nivalenol. World Mycotoxin J. 3, 323-347. doi: 10.3920/ WMJ2010.1247

Poppenberger, B., Berthiller, F., Lucyshyn, D., Sieberer, T., Schuhmacher, R., Krska, R., et al. (2003). Detoxification of the Fusarium mycotoxin deoxynivalenol by a UDP-glucosyltransferase from Arabidopsis thaliana. J. Biol. Chem. 278, 47905-47914. doi: 10.1074/jbc.M307552200

Pronyk, C., Cenkowski, S., and Abramson, D. (2006). Superheated steam reduction of deoxynivalenol in naturally contaminated wheat kernels. Food Control 17, 789-796. doi: 10.1016/j.foodcont.2005.05.004

Rocha, O., Ansari, K., and Doohan, F. M. (2005). Effects of trichothecene mycotoxins on eukaryotic cells: a review. Food Addit. Contam. 22, 369-378. doi: $10.1080 / 02652030500058403$

Savard, M. E., and Blackwell, B. A. (1994). "Spectral characteristics of secondary metabolites from Fusarium fungi," in Mycotoxins in Grain, eds J. D. Miller and H. L. Trenholm (St. Paul, Minnesota: Eagen Press), $59-228$.

Savard, M. E., Blackwell, B. A., and Greenhalgh, R. (1987). An 1H nuclear magnetic resonance study of derivatives of 3-hydroxy-12,13-epoxytrichothec-9-enes. Can. J. Chem. 65, 2254-2262. doi: 10.1139/v87-376
Schatzmayr, G., Zehner, F., Täubel, M., Schatzmayr, D., Klimitsch, A., Loibner, A. P., et al. (2006). Microbiologicals for deactivating mycotoxins. Mol. Nutr. Food Res. 50, 543-551. doi: 10.1002/mnfr.200500181

Shank, R. A., Foroud, N. A., Hazendonk, P., Eudes, F., and Blackwell, B. A. (2011). Current and future experimental strategies for structural analysis of trichothecene mycotoxins-a prospectus. Toxins 3, 1518-1553. doi: $10.3390 /$ toxins 3121518

Shifrin, V. I., and Anderson, P. (1999). Trichothecene mycotoxins trigger a ribotoxic stress response that activates c-Jun $\mathrm{N}$-terminal kinase and p38 mitogen-activated protein kinase and induces apoptosis. J. Biol. Chem. 274, 13985-13992. doi: 10.1074/jbc.274.20.13985

Shin, S., Torres-Acosta, J. A., Heinen, S. J., McCormick, S., Lemmens, M., Paris, M. P. K., et al. (2012). Transgenic Arabidopsis thaliana expressing a barley UDPglucosyltransferase exhibit resistance to the mycotoxin deoxynivalenol. J. Exp. Bot. 63, 4731-4740. doi: 10.1093/jxb/ers141

Stanic, A., Uhlig, S., Solhaug, A., Rise, F., Wilkins, A. L., and Miles, C. O. (2015). Nucleophilic addition of thiols to deoxynivalenol. J. Agric. Food Chem. 63, 7556-7566. doi: 10.1021/acs.jafc.5b02864

Steinmetz, W. E., Robustelli, P., Edens, E., and Heineman, D. (2008). Structure and conformational dynamics of trichothecene mycotoxins. J. Nat. Prod. 71, 589-594. doi: 10.1021/np070562x

Tittlemier, S. A., Sobering, D., Bowler, K., Zirdum, T., Gaba, D., Chan, J. M., et al. (2014). By-products of grain cleaning: an opportunity for rapid sampling and screening of wheat for mycotoxins. World Mycotoxin J. 8, 45-53. doi: 10.3920/WMJ2014.1760

Ueno, Y., Hosoya, M., Morita, Y., Ueno, I., and Tatsuno, T. (1968). Inhibition of the protein synthesis in rabbit reticulocyte by nivalenol, a toxic principle isolated from Fusarium nivale-growing rice. J. Biochem. 64, 479-485.

Conflict of Interest Statement: The authors declare that the research was conducted in the absence of any commercial or financial relationships that could be construed as a potential conflict of interest.

Copyright (๑) 2016 Foroud, Shank, Kiss, Eudes and Hazendonk. This is an open-access article distributed under the terms of the Creative Commons Attribution License (CC $B Y$ ). The use, distribution or reproduction in other forums is permitted, provided the original author(s) or licensor are credited and that the original publication in this journal is cited, in accordance with accepted academic practice. No use, distribution or reproduction is permitted which does not comply with these terms. 